\title{
eNeuro
}

Research Article: New Research / Cognition and Behavior

\section{Electrophysiological Responses to Rapidly- Presented Affective Stimuli Predict Individual Differences in Subsequent Attention}

https://doi.org/10.1523/ENEURO.0285-21.2021

Cite as: eNeuro 2021; 10.1523/ENEURO.0285-21.2021

Received: 30 June 2021

Revised: 18 November 2021

Accepted: 24 November 2021

This Early Release article has been peer-reviewed and accepted, but has not been through the composition and copyediting processes. The final version may differ slightly in style or formatting and will contain links to any extended data.

Alerts: Sign up at www.eneuro.org/alerts to receive customized email alerts when the fully formatted version of this article is published.

Copyright (C) 2021 Song et al.

This is an open-access article distributed under the terms of the Creative Commons Attribution 4.0 International license, which permits unrestricted use, distribution and reproduction in any medium provided that the original work is properly attributed. 
1

3

4

5

6

7

8

9

\section{Manuscript Title:}

Electrophysiological Responses to Rapidly-Presented Affective Stimuli Predict Individual Differences in Subsequent Attention

\section{Abbreviated Title:}

Effects of emotions on subsequent attention

\section{List all Author Names and Affiliations:}

Ha Neul Song ${ }^{1,2}$, Sewon $\mathrm{Oh}^{3}$, Sang Ah Lee $\mathrm{L}^{1,2}$

Department of Brain and Cognitive Sciences, Seoul National University, Seoul 08826, Republic of Korea ${ }^{1}$

Department of Bio and Brain Engineering, Korea Advanced Institute of Science and Technology, Daejeon 34141, Republic of Korea²

Department of Psychology, University of South Carolina, Columbia, SC 29208, USA ${ }^{3}$

4. Author Contributions: SAL and HNS designed the research; HNS and SO performed the experiments; HNS analyzed the data; SAL, HNS, SO wrote the paper.

\section{Correspondence should be addressed to:}

Sang Ah Lee

Department of Brain and Cognitive Sciences

Seoul National University

Gwanak-ro 1, Gwanak-gu, Seoul 08826, Republic of Korea

sangahlee@snu.ac.kr 


\section{Number of Figures: 4}

7. Number of Tables: 3

8. Number of Multimedia: 0

9. Number of words for Abstract: 250

10. Number of words for Significance Statement: 117

11. Number of words for Introduction: 812

12. Number of words for Discussion: 1,149

\section{Acknowledgments}

We are grateful to the members of the Developmental Cognitive Neuroscience Laboratory at SNU, including Y. J. Rah, S. Park, and J. Lee for their assistance in data analysis and Professors J. Jeong and S. H. Lee for their comments on an earlier version of this work.

\section{Conflict of Interest}

Authors report no conflict of interest.

\section{Funding sources}

This research was supported by grants to SAL from National Research Foundation of Korea (2021M3A9E408078011), Hyundai NGV (Project of neuro-cognitive/affective modulation in automobile environment), The KAIST Center for Contemplative Science. 


\section{Electrophysiological Responses to Rapidly-Presented Affective Stimuli}

\section{Predict Individual Differences in Subsequent Attention}

\section{Abstract}

We are constantly surrounded by a dynamically changing perceptual landscape that can influence our behavior even without our full conscious awareness. Emotional processing can have effects on subsequent attention, but there are mixed findings on whether it induces attentional enhancement or interference. The present study used a new multimodal approach to explain and predict such attentional effects based on individual differences in responses to emotional stimuli. We briefly presented affective pictures (neutral, positive, erotic, mutilation, and horror categories) for 80 ms, immediately followed by a cued flanker task that was unrelated to the pictures. Event-related potentials (ERP), skin conductance response (SCR), and reaction time (RT) were measured for each participant. We found that, in general, affective pictures induced higher electrophysiological responses compared to neutral pictures (P300 and late positive potential (LPP) in the erotic condition; P300, LPP, and SCR in the horror condition). In particular, individuals who showed a strong ERP response to the pictures were impeded in the erotic condition (only P300) and facilitated in the horror condition (both P300 and LPP). Those who did not show a significant ERP or SCR response to the pictures were facilitated in the erotic condition and impeded in the horror condition. Furthermore, it was possible to classify the direction of the attentional effect in the erotic and horror conditions from the participants' P300, LPP, and SCR responses. These results demonstrate that underlying individual differences in emotional processing must be considered in understanding and predicting the effects of emotions on attention and cognition. 
Automatic influence of emotions on subsequent attention may be adaptive for fast behavioral response to environmental stimuli. The majority of past studies have claimed that pleasant emotions facilitate subsequent attention and that unpleasant emotions impede it. However, several studies directly contradicted such findings by reporting opposite effects, with pleasant pictures impeding attention and unpleasant pictures facilitating it. Our results resolve this discrepancy in the existing literature by showing that depending on how weakly or strongly someone responds to emotional stimuli (erotic and horror categories), they may be either facilitated or distracted in their subsequent attention.

75 Furthermore, we were able to accurately classify the direction of this attentional effect using their ERP and SCR responses to the pictures. 


\section{Introduction}

Recently, research in brain and cognitive sciences has started to interface closely with applications for improving cognition and mental health. One way in which such tools are used is for personal emotion monitoring and regulation. Most current technology, however, require that users explicitly recognize their internal states (e.g, through self-report). Yet, in everyday life, people are constantly bombarded by rapidly changing perceptual stimuli that may trigger brain processes which can influence them even while they are engaged in other tasks (Bradley, 2009; Compton, 2003; Halgren, 1992; LeBlanc et al., 2015; Moser et al., 2010; Pourtois et al., 2013; Vuilleumier, 2005; Vuilleumier \& Driver, 2007). For example, after passing an animal on the side of the road, a driver may become momentarily susceptible to missing a turn or getting into an accident without fully being aware of what he saw. Subsequent attentional effects of emotional stimuli can vary depending on the individual; in the situation described above, some people may become more alert while others get distracted after passing the scene. Although individual differences in emotional processing have been studied extensively, there is a lack of understanding on how such differences influence attention (Gohm \& Clore, 2000; Hamann \& Canli, 2004; Mardaga et al., 2006; Matusz et al., 2015; Zhang \& Zhou, 2014).

Emotional processing consists of detecting and responding to (e.g., via arousal and regulation) emotionally significant perceptual stimuli and can have multiple pathways by which it affects subsequent attention (Pourtois et al., 2013). Because such processes can happen quickly, quantifying these processes requires measures with high temporal resolution. Event-related potentials (ERPs) in response to emotional stimuli provide a simple and fast marker of cortical activity (Greg Hajcak et al., 2013) that can be easily acquired using a variety of EEG systems. According to previous studies, P300 amplitude correlates with perceived emotional significance and Late Positive Potential (LPP) amplitude with emotion regulation (Cuthbert et al., 2000; Foti \& Hajcak, 2008; Hajcak \& Foti, 2020; Hajcak et al., 2010; Johnston et al., 1986). In addition, Skin Conductance Response (SCR), which indicates activity of 
the sympathetic nervous system and is associated with hypothalamic arousal, has a slower progression and is longer-lasting compared to ERPs (Critchley et al., 2000; Cuthbert et al., 2000). As different aspects of emotional processing are reflected in each physiological marker, a multimodal approach using ERP and SCR may enhance our ability to explain and predict the cognitive effects of emotional processing at the individual level.

Given that fast processing of emotions are adaptive mechanisms for subsequent behavioral responses, it seems reasonable for even quickly presented emotional stimuli to modulate attention; however, there have been mixed findings on the direction of such effects (Bocanegra \& Zeelenberg, 2009, 2011; Ortner et al., 2013; Schmeichel, 2007). Furthermore, while electrophysiological correlates of attention to emotional stimuli themselves have been well-documented (e.g., N2, EPN, LPP), their relevance to subsequent attention on an unrelated task has not yet been characterized extensively (G. Hajcak et al., 2013; Krolak-Salmon et al., 2001; Olofsson et al., 2008; Pourtois et al., 2004; Sabatinelli et al., 2007; Wiens et al., 2011). Some studies reported that pleasant emotional stimuli facilitate subsequent attention and that unpleasant stimuli impede it (Eastwood et al., 2003; Friedman \& Forster, 2010; LeBlanc et al., 2015; Wadlinger \& Isaacowitz, 2006). However, others have yielded contrary results. In one study, images of fearful faces enhanced, rather than decreased, performance in a perceptual attention task (Phelps et al., 2006). Another study reported that briefly-presented sexual stimuli decreased performance in a dot detection task; interestingly, the magnitude of this effect was correlated with self-reports of eroticism (Prause et al., 2008).

One overlooked factor is that individual differences may not only explain the magnitude of such effects but also their direction (facilitation vs. impediment). Because the same emotional stimulus can elicit varied responses across individuals according to their personal characteristics or experiences, the current study investigated individual differences in the interaction between emotional processing and attention and hypothesized that people whose attention was facilitated by affective pictures would 
125 show dissociable physiological responses from those who were impeded by it. Through this investigation

126 we aimed not only to provide insight into the mechanisms underlying the interaction between emotion

127 and cognition but to also improve personalization of neurotechnology and its real world applicability.

128

131

132

133

134

To simulate situations in which attention is automatically influenced by rapid emotional processing, we briefly presented affective pictures prior to teach trial of a cued flanker task (Fan et al., 2005; Fan et al., 2002). Neutral, positive, erotic, mutilation, and horror picture stimuli were used to elicit a variety of potentially emotion-dependent effects. To explore individual differences, we divided people into two groups based on whether they were facilitated or impeded by certain picture categories and compared their ERP and SCR measures. Finally, we tested whether these physiological markers can accurately classify and predict these attentional effects at the individual level. 


\section{Methods}

\section{Participants}

Participants were thirty-one university students (19 males, mean age $24.77, S D=3.74$ ) recruited from in a location which will be identified if the article is published. All participants were right-handed and had normal or corrected vision. Data from all subjects were included in the group analysis of data involving SCR and reaction time (RT). Data from five participants were excluded from the analysis of EEG data due to a failure to acquire usable data (disrupted connection or interrupted testing session), resulting in a final sample size of 26 (14 males). All participants' anxiety and depression scores were measured via Beck Anxiety Inventory (BAI) and Beck Depression Inventory-II (BDI-II); no participants were found to have severe anxiety or depression (Beck et al., 1988; Beck et al., 1996).

Supporting data were collected from three separate independent samples: picture stimuli valence/arousal rating $(n=10$, mean age $=23.20, S D=2.44)$, picture awareness and memory test $(n=17$, mean age $=22.35, S D=4.27)$, and a partial replication of the findings using a 32-channel wired EEG system ( 8 males, mean age $=28.35, S D=4.19$ ).

\section{Materials and Procedures}

We aimed to induce rapid emotional processing via brief presentations of visual scenes immediately followed by a trial of a cued flanker task (Attention Network Task, ANT (Fan et al., 2005; Fan et al., 2002)). On each trial, the affective picture was presented for $80 \mathrm{~ms}$ (see Figure $\mathbf{1 A}$ and Figure 4 for more information), followed by a randomized fixation period between $900 \mathrm{~ms}$ and $1300 \mathrm{~ms}$ long. For cued trials, an asterisk appeared for $100 \mathrm{~ms}$ (either above, center, or below the fixation point) and, after 400ms of fixation, the target was presented. The ANT task, designed to engage multiple attentional 
mechanisms, employed a center asterisk (center cue) to give participants temporal information about the target presentation, and the placement of the asterisk above or below the center fixation point (spatial cue) additionally provides information about where the target will appear. The target was the center arrow of a row of five arrows; on congruent trials, the flanker arrows were consistent with the direction of the target arrow, and on incongruent trials, they pointed in the opposite direction. Subjects were asked to indicate the direction of the target arrow as quickly as possible; if they did not respond within $1700 \mathrm{~ms}$, the fixation period for the next trial started automatically. RT on each trial was recorded and log transformed for data analysis to minimize skewed distribution of each participant's data. After the subjects made a response, the arrows disappeared and a fixation period followed.

Before the start of the test session, participants were given 20 practice trials to familiarize themselves with the task flow. The main task consisted of 10 blocks of 24 trials each. Two-minute-long breaks were given between the blocks. Each emotion condition (neutral, positive, erotic, mutilation, and horror) was tested across two blocks, once in the first half of the session and another in the second half. The order of the blocks within each half was randomized, with the restriction that the same emotion condition block did not appear in succession (i.e., fifth and sixth blocks were not the same). During the task, EEG, SCR (right-side two fingers in hardware), and RT (button with left hand) were recorded simultaneously.

With the exception of the pictures in the horror condition, all pictures were selected from the International Affective Picture System (IAPS) which is a commonly used image database for emotion research and contains the standardized valence score and situational category of each picture (Lang et al., 2008). For the neutral condition, pictures in the median $20 \%$ of IAPS valence scores were selected, excluding those containing images of people, weapons, cigarettes, and food, to avoid socially biased effects. From pictures with top $20 \%$ valence scores in the IAPS category, those of intimately engaged heterosexual couples were selected for the erotic condition, and those excluding sexual content were 
selected for the positive condition. The mutilation condition consisted of images of bodily damage/harm selected based on the IAPS picture descriptions. Since the fear-inducing pictures included in IAPS were inadequate to be categorized as "horror", the horror condition pictures were selected from a commercially usable free web source. The horror pictures' comparability to other conditions was confirmed before the main task (Figure 1B). A separate group of ten participants rated the valence and arousal of all of the pictures in our stimulus set, after each picture was presented for $3 \mathrm{~s}$ on a computer monitor in front of them (Bradley \& Lang, 1994). Altogether, 240 pictures were used, 48 from each emotion condition.

\section{SCR data acquisition}

SCR (galvanic skin response) was measured to detect the release of sweat due to a change in the arousal state (Montagu \& Coles, 1966), using the Gazepoint biometrics package and software, with a constant voltage coupler $(5 \mathrm{~V})$ and a $60 \mathrm{~Hz}$ sampling rate. Participants put their right index and middle fingers into the biometric hardware and were instructed to pull out their fingers between task blocks to prevent the physiological response from saturation. To calculate SCR for each picture, a high-pass FIR filter of $0.05 \mathrm{~Hz}$ was applied (Matlab) to the entire time series; then, maximum change in SCR was extracted from the baseline (average over the $500 \mathrm{~ms}$ fixation period preceding picture onset) to the test trial (from picture onset to $500 \mathrm{~ms}$ before the next trial). The data were log-transformed to minimize skewed response and averaged for each block (for multimodal classification) and each emotional condition (for the remainder of the analysis).

EEG data acquisition and processing 
Participants' EEG signal was recorded using the gel-type 32-channel wireless Emotiv EPOC Flex that adheres to the 10-20 system, a standard method for electrode placement. The data were preprocessed through average re-referencing and bandpass filtering between $0.1 \mathrm{~Hz}$ and $30 \mathrm{~Hz}$ using EEGLAB on MATLAB (Delorme \& Makeig, 2004). Based on the picture presentation at Oms, ERP epochs were selected from $-100 \mathrm{~ms}$ to $1000 \mathrm{~ms}$. Baseline (from $-100 \mathrm{~ms}$ to $0 \mathrm{~ms}$ ) correction was applied in each epoch. Epochs containing ocular artifacts (identified through Infomax ICA) or signals with an absolute value higher than $100 u V$ were omitted from the analysis (Delorme et al., 2007). Three channels (Fz, Cz, and Pz) were selected for ERP component analysis (Codispoti et al., 2006; Cuthbert et al., 1998; Stormark et al., 1995; Yen et al., 2010). P300 and LPP amplitudes were calculated by the mean voltage between $250 \mathrm{~ms}$ and $350 \mathrm{~ms}$ and between $500 \mathrm{~ms}$ and $800 \mathrm{~ms}$, respectively; these time-points were chosen based on previous literature (Lu et al., 2011; Maffei et al., 2021; Zhang \& Zhou, 2014; Zhao et al., 2018) and our study design in which the ANT began at least $900 \mathrm{~ms}$. To test for the effects of emotional stimuli, the three types of responses (RT, SCR, ERP) in the four emotion conditions (positive, erotic, mutilation, and horror) were compared with those in the neutral condition (see below for a description of notation (Schupp, Flaisch, et al., 2006; Schupp et al., 2003; Schupp, Stockburger, et al., 2006)). Bonferroni correction was applied to the $p$-value of $E_{\text {modality, emotion }}$ based on the number of multiple comparisons following the repeated-measures ANOVA.

$E_{\text {modality, emotion }}=\boldsymbol{R}_{\text {modality, emotion }}-\boldsymbol{R}_{\text {modality, neutral }}$

$E$ : Effect of affective stimuli compared to the neutral condition

$\boldsymbol{R}$ : response value in each modality and condition

modality: RT, SCR, or ERP

emotion: positive, erotic, mutilation, or horror 
228 were divided into two groups based on whether they were facilitated (ERT, emotion $<0$ ) or impeded

229 (ERT, emotion > 0) attention. A support vector machine (SVM) was used to classify the subjects, based

230 on their ERP (unimodal) or both ERP and SCR (multimodal), to predict whether RT in the emotion

231 condition will be faster or slower than that in the neutral condition (Noble, 2006). Block-averaged values were used for each variable. In each condition, prediction and accuracy and area under the receiver operating characteristic (ROC) curve (AUC) were calculated via SVM with 10-fold cross-validation. 
Results

\section{Behavioral Performance}

Before the main experiment, we compared the valence and arousal ratings of the picture stimuli across all conditions; this was particularly relevant with respect to the horror condition, which was not a part of the IAPS. Friedman's tests revealed a main effect of the emotion condition for both valence ratings (Figure $1 C ; X^{2}=38.000, p<0.001$ ) and arousal ratings (Figure $1 D ; X^{2}=29.760, p<0.001$ ). As expected, post-hoc Wilcoxon signed rank showed that horror pictures were rated significantly lower in valence than neutral, positive, and erotic pictures but not different from mutilation pictures. For arousal ratings, the horror condition was significantly higher than the neutral condition but not different from other emotion conditions (Table 1).

A three-way repeated measures ANOVA including the emotion condition (neutral, positive, erotic, mutilation, and horror), cue condition (spatial, center, and no), and target condition (congruent and incongruent) was conducted to analyze their effects on RT and make sure that the cue and target in our modified ANT worked properly. There were main effects of the cue and target conditions on RT

(Figure 2A; $F(1.601,48.025)=49.605, p<0.001, \eta_{p}{ }^{2}=0.213 ;$ Figure 2B; $F(1,30)=8.109, p=0.008, \eta_{p}{ }^{2}=$ 0.623). For post-hoc pairwise t-tests, RT after the spatial cue was faster than that after both the center cue $\left(t(30)=-5.871, p_{\text {corrected }}<0.001, d=-1.054\right)$ and no cue $\left(t(30)=-8.659, p_{\text {corrected }}<0.001, d=-1.555\right)$. RT following the center cue was faster than no cue $\left(t(30)=-4.517, p_{\text {corrected }}<0.001, d=0.811\right)$. RT toward the congruent target was also faster than that toward the incongruent target $\left(\mathrm{t}(30)=-2.826, \mathrm{p}_{\text {corrected }}=\right.$ $0.008, d=-0.508)$. There was a main effect of emotion, but no significant results in post-hoc pairwise comparisons $\left(F(4,120)=2.839, p=0.027, \eta_{p}{ }^{2}=0.086\right)$. The results showed that participants were able to correctly perform the ANT using the cue information and the congruency of arrows. 
To test whether RT in each of the positive, erotic, mutilation, and horror conditions were different from that in the neutral condition, a one-sample t-test with 0 was conducted the RT difference score $E_{R T, \text { emotion }}$ in each emotion category. There were no significant differences (Table 2).

\section{Skin Conductance Response (SCR)}

To test whether SCR in each of the positive, erotic, mutilation, and horror conditions was different from that in the neutral condition, a one-sample t-test with 0 was conducted on the SCR difference score $E_{S C R \text {, emotion }}$ in each emotion category. SCR in the horror condition was higher than that in the neutral condition (Figure $2 \mathrm{C} ; \mathrm{t}(30)=2.675, \mathrm{p}_{\text {corrected }}=0.048, \mathrm{~d}=0.481$ ). Furthermore, a one-way repeated measures ANOVA revealed a significant effect of the emotion condition on $\operatorname{SCR}(F(3,90)=$ 4.955, $\mathrm{p}=0.003, \eta_{\mathrm{p}}{ }^{2}=0.142$ ), with post-hoc pairwise t-test showing that $E_{S C R \text {, horror }}$ was higher than $E_{S C R}$, positive and $E_{S C R \text {, erotic }}$ (Table 2). The results indicated that the physiological arousal was significantly elicited in the horror condition.

\section{ERP response}

To test whether P300 amplitude in each of the positive, erotic, mutilation, and horror conditions was different from that in the neutral condition, a one-sample t-test with 0 was conducted on the P300 difference score $E_{P 300, \text { emotion }}$ in each emotion condition and channel (Figure 2E). In channel Fz, P300 amplitude in the horror condition was higher than that in the neutral condition $\left(t(25)=3.387, \mathrm{p}_{\text {corrected }}=\right.$ 0.009, $d=0.664)$. In channel $\mathrm{Cz}, \mathrm{P} 300$ amplitude in the erotic condition was higher than that in the neutral condition $\left(t(25)=2.923, p_{\text {corrected }}=0.029, d=0.573\right)$. To differentiate emotional effects on P300 amplitude, a two-way repeated measures ANOVA including the emotion condition (positive, erotic, 
mutilation, and horror) and channel ( $\mathrm{Fz}, \mathrm{Cz}$, and $\mathrm{Pz})$ was performed. There was a main effect of emotion condition $\left(F(3,75)=9.065, p<0.001, \eta_{p}^{2}=0.266\right)$. Since there was no main effect of channel, the P300 amplitudes in channel $\mathrm{Fz}, \mathrm{Cz}$, and $\mathrm{Pz}$ were averaged for a post-hoc pairwise t-test. $E_{P 300, \text { erotic }}$ was higher

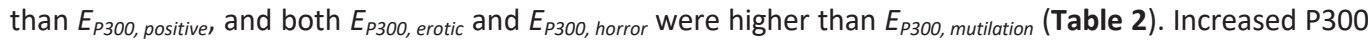
amplitude for only the erotic and horror pictures may indicate that participants processed the emotional significance of these particular visual stimuli even after a brief presentation.

For LPP amplitude, likewise, the one-sample t-test against 0 was conducted on the LPP difference score $E_{L P P}$, emotion in each emotion condition and channel (Figure 2F). LPP amplitude in both the erotic and horror conditions was higher than that in the neutral condition in channel $\mathrm{Pz}(\mathrm{t}(25)=6.708$, $\left.\mathrm{p}_{\text {corrected }}<0.001, \mathrm{~d}=1.316 ; \mathrm{t}(25)=3.258, \mathrm{p}_{\text {corrected }}=0.010, \mathrm{~d}=0.639\right)$, while only the erotic condition was higher than the neutral condition in channel $\mathrm{Cz}\left(\mathrm{t}(25)=5.924, \mathrm{p}_{\text {corrected }}<0.001, \mathrm{~d}=1.162\right)$. To differentiate emotional effects on LPP amplitude, a two-way repeated measures ANOVA including the emotion condition (positive, erotic, mutilation, and horror) and channel ( $\mathrm{Fz}, \mathrm{Cz}$, and $\mathrm{Pz}$ ) was performed. There were main effects of both channel and emotion condition with interaction between them $\left(F(1.164,27.937)=7.019, p=0.010, \eta_{p}{ }^{2}=0.226 ; F(3,72)=5.598, p=0.002, \eta_{p}{ }^{2}=0.189 ; F(2.753,63.070)\right.$ $\left.=3.998, p=0.013, \eta_{p}^{2}=0.143\right)$. For the post-hoc pairwise t-test, both in channel $C z$ and $P z, E_{L P P, \text { erotic }}$ and $E_{L P P, \text { horror }}$ were higher than $E_{L P P, \text { positive }}$ (Table 2). Increased LPP amplitude after seeing the erotic and horror pictures may reflect emotional arousal and regulation in these conditions.

\section{Facilitated or impeded attention and its prediction}

Based on RT in the neutral condition $\left(E_{R T \text {, emotion }}=0\right)$, participants were divided into two groups (facilitated vs. impeded) in the erotic and horror conditions (Figure 3A). Out of 26 participants, 13 were facilitated and the remaining 13 were disrupted in each condition (Figure 3B). A nonparametric one- 
sample test (Wilcoxon signed rank test) against 0 was conducted on $E_{P 300, \text { emotion }}$ and $E_{L P P, \text { emotion. }}$ In the erotic condition (Figure $\mathbf{3 C}$ ), compared to the neutral condition, only participants showing impeded attention had higher P300 amplitude in response to the affective pictures in channels $\mathrm{Fz}$ and $\mathrm{Cz}(\mathrm{Z}=$ 2.551, $\left.\mathrm{p}_{\text {corrected }}=0.022, \mathrm{r}=0.708 ; \mathrm{Z}=3.180, \mathrm{p}=0.003, \mathrm{r}=0.882\right)$. On the other hand, LPP amplitude increased in participants showing both facilitated and impeded attention in channels $\mathrm{Cz}$ and $\mathrm{Pz}(\mathrm{Z}=$ 2.551, $p_{\text {corrected }}=0.011, r=0.708 ; Z=3.110, p_{\text {corrected }}=0.003, r=0.863 ; Z=3.110 ; p_{\text {corrected }}=0.003, r=$ 0.863; $Z=3.040, p_{\text {corrected }}=0.003, r=0.843$ ). In the horror condition (Figure 3D), compared to the neutral condition, only participants whose attention was facilitated showed higher P300 amplitude in channel Fz $\left(Z=2.341, p_{\text {corrected }}=0.038, r=0.649\right)$ and higher LPP amplitude in channel Pz $\left(Z=2.271, p_{\text {corrected }}=0.046\right.$, $r=0.630)$. There were no differences of SCR, anxiety and depression scores, and gender between facilitated and impede groups in the erotic and horror conditions each. To sum up, distraction in the erotic condition and facilitation in the horror condition showed distinct ERP profiles. In addition, an identical experiment was conducted with an independent sample of 15 participants using a 32-channel EEG system (Neuroscan Grael and Curry 8 EEG software) for a partial replication of the original results. In the erotic condition, 9 subjects were facilitated and 6 were disrupted (compared to the neutral condition); in the horror condition, 8 were facilitated and 7 were disrupted. Again, in the erotic condition, compared to the neutral condition, only participants showing impeded attention had higher P300 and LPP amplitude in channel $C Z(Z=1.992, p=0.046, r=0.813 ; Z=2.201, p=0.028, r=0.899)$, while in the horror condition, participants whose attention was facilitated attention showed a tendency of higher P300 and LPP amplitude $(Z=1.820, p=0.069, r=0.644 ; Z=1.820, p=0.069, r=0.644)$. Although slightly underpowered, these results suggest that our finding of the "cognotypes" in emotionattention interaction are widespread and replicable. 
Given the lack of a difference across channels in the repeated measures ANOVA and post-hoc pairwise t-test, $E_{P 300, \text { emotion }}$ in channels $\mathrm{Fz}, \mathrm{Cz}$, and $\mathrm{Pz}$ and $E_{L P P}$, emotion in channels $\mathrm{Cz}$ and $\mathrm{Pz}$ were averaged for P300 and LPP features. P300 and LPP were used as features for unimodal classification, and P300, LPP, and SCR were used as features for multimodal classification. In a unimodal classification based only on ERP measures, accuracy values from SVM, predicting whether attention would be facilitated or impeded were $53.0 \%$ (positive), $66.0 \%$ (erotic), 51.0\% (mutilation), and 65.5\% (horror). Mean 10-fold AUC values were 0.63 (positive), 0.73 (erotic), 0.48 (mutilation), and 0.76 (horror). On the other hand, in a multimodal classification based on ERP and SCR, accuracy values from SVM classifying whether attention would be facilitated or impeded were $56.17 \%$ (positive), $70.50 \%$ (erotic), $51.00 \%$ (mutilation), and $73.50 \%$ (horror). Mean 10-fold AUC values were 0.68 (positive), 0.74 (erotic), 0.46 (mutilation), and 0.81 (horror). The prediction of the direction of attentional effects in the erotic and horror conditions was significantly above chance level, $50 \%(t(9)=3.706, p=0.005 ; t(9)=4.045, p=0.003)$. Moreover, in a comparison of the unimodal and multimodal classification, overall accuracy and AUC were increased when SVM was performed with ERP and SCR (Table 3).

\section{Picture awareness ratings and recognition test}

An additional supplementary experiment was conducted to see how participants processed the affective pictures in the present study. As in the original experiment, an affective picture was presented for $80 \mathrm{~ms}$ and followed immediately by a trial of the attention task (Figure 4A). However, after each trial was completed, subjects were asked to answer several questions on the level of detail with which they perceived the picture and how much emotion was elicited by it. Five types of pictures (neutral, positive, erotic, mutilation, and horror) were used and each type consisted of 12 pictures from our original stimulus set. We found that participants were able to report the general gist of the pictures and their 
347

348

349

350

351

352

353

354

355

356

subjective feeling of arousal, but were not able to recall them in detail, regardless of picture type (Figure 4B). After performing all 60 trials, they were also asked about how they thought their reaction time was influenced by the affective pictures (facilitated vs. impeded); only four participants in the erotic condition and eight in the horror condition answered correctly (Figure 4C). In the second part of the experiment, half of the previously presented pictures and novel lure pictures in the same category were presented one by one as a recognition task in which subjects answered whether or not they had seen the picture in the first part of the experiment. Recognition accuracies of all types of pictures were not significantly higher than chance level, 50\% (Figure 4D; $t(16)=-0.436, p_{\text {corrected }}=1, d=-0.106 ; t(16)=$ 1.022, $\mathrm{p}_{\text {corrected }}=0.966, \mathrm{~d}=0.248 ; \mathrm{t}(16)=-10.661, \mathrm{p}_{\text {corrected }}<0.001, \mathrm{~d}=-2.586 ; \mathrm{t}(16)=-0.623, \mathrm{p}_{\text {corrected }}=1$, $\left.d=-0.151 ; t(16)=-1.578, p_{\text {corrected }}=0.537, d=-0.383\right)$ 


\section{Discussion}

Through an investigation of individual differences, the present study clarifies previous mixed findings concerning subsequent attentional effects of emotional processing. Prior to our study, the question of whether emotional processing induced attentional assistance or interference was inconclusive. We found that neurophysiological responses to emotional processing in the erotic and horror conditions were reflected in ERP and SCR measures. Importantly, it was possible to predict individual differences in the direction of subsequent attentional effect from the ERP and SCR measures, particularly in response to erotic and horror pictures.

\section{Salient emotion conditions}

Significant P300, and LPP were elicited and reliably predictable only in the erotic and horror conditions. Hajcak et al. (2010) pointed out that P300 amplitude is related to perceiving emotional significance and that LPP amplitude indicates emotional arousal and regulation. Moreover, the timing of the LPP is purported to reflect cognitive load. The higher LPP amplitude that we observed at $500 \mathrm{~ms}$ $800 \mathrm{~ms}$ following the picture presentation can be additionally interpreted as the processing of emotional information with a cognitive demand. Although this is a possibility, our supporting experiment showing participants' failure in a subsequent recognition memory test suggests that higher memory processes were not involved in the timeframe we provided in our task (see Figure 4). Therefore, rather than explicit emotional reappraisal or contextual memory processing, LPP may reflect a rapid emotional arousal regulation. According to this interpretation, the effects found in the erotic and horror conditions could reflect the perceptual significance of the stimuli (as indicated by the P300 response), followed by an automatic, rapid regulatory process before the attention task began (as indicated by the LPP response). 
In past studies, explicit affective stimuli have been reported to elicit higher P300 or LPP amplitude than neutral stimuli, regardless of the specific emotional category (Bradley et al., 2001; Bradley \& Lang, 2000; Cuthbert et al., 2000; Hajcak et al., 2010; Lang et al., 1997; Lang et al., 1998; Lang et al., 1993; Naumann et al., 1992). Furthermore, the increase in P300 and LPP amplitudes after rapid unpleasant stimuli were found to be weaker compared to the response to explicit stimuli (Ito \& Cacioppo, 2000; Lin et al., 2018; Van Strien et al., 2010). Thus, our results suggest that only stimuli which are salient or potentially important may overcome the threshold for eliciting P300 or LPP. For instance, it is plausible that environmental stimuli related to mating opportunities or potentially harmful situations (as in the erotic and horror conditions) would be processed more quickly and effectively than others, but perhaps due to different pathways of attentional modification.

In this sense, horror stimuli signifying a threat-related situational context might strongly elicit both cortico-limbic and sympathetic nervous system responses, reflected in the ERPs and SCR (Baumgartner et al., 2006; Carretie et al., 2004; Northoff et al., 2000). According to the Multiple Attention Gain Control (MAGiC) model (Pourtois et al., 2013), attentional processes can be enhanced indirectly by a mechanism of visual perception amplification triggered by emotion signals from the amygdala (that then consequently enhances performance in tasks requiring visual attention). The erotic condition, on the other hand, may modulate attention through a slightly different pathway that directly activates cortical attentional processes; one study, for instance, found that visual erotic stimuli activated the dorsolateral prefrontal cortex, which is known to play a crucial role in selective attention, and that this activation was sustained even after the stimulus disappeared (Leon-Carrion et al., 2007). This interpretation may explain why only people who responded significantly to the erotic stimulus showed a reduction in performance in the subsequent attention task. 
Individual differences in the direction of attentional effects

Past research reported mixed findings on the direction of the effect of emotion on attention (Bocanegra \& Zeelenberg, 2009, 2011; Brosch et al., 2013; Domınguez-Borras \& Vuilleumier, 2013; Ortner et al., 2013; Pourtois et al., 2013; Prause et al., 2008; Rossignol et al., 2012; Schmeichel, 2007). In our findings, attentional performance of some partipants was facilitated and that of others was impeded, depending on the erotic and horror conditions. This variation might be explained by differences in emotional response based on personal experiences and inclination towards the emotional stimuli in our task (Matusz et al., 2015; Zhang \& Zhou, 2014). For example, a past study reported that people who are afraid of snakes or spiders show a selectively higher LPP response to pictures of the particularly threatening objects than those who are not (Kolassa et al., 2005; Miltner et al., 2005).

In our study, LPP response to erotic pictures increased regardless of whether attention was facilitated or impeded, but P300 amplitude increased only for subjects who were impeded in the attention task. We interpret these results to mean that erotic pictures required emotion regulation in general, while they impeded subsequent attention only when people responded more strongly to them. In contrast, in the horror condition, both P300 and LPP amplitudes increased only for facilitated attention. It is possible that, although unpleasant stimuli are distracting in general, for individuals who are particularly responsive to the horror stimuli, they can assist subsequent attention (i.e., getting scared may enhance visual perception (Bocanegra \& Zeelenberg, 2009; Mobbs et al., 2009; Phelps et al., 2006; Pourtois et al., 2013)).

\section{Limitations}

Our findings imply that there are certain types of people whose attentional effects of emotional processing can be dissociable depending on the emotion type. In particular, their initial responses (P300) 
were highly indicative of the direction of attentional effects. However, in our study, we did not find a significant effect of the participants' anxiety and depression scores. Nevertheless, there may be more complex factors contributing to individual sensitivity to specific types of emotional stimuli. Further investigations will delve into identifying these key factors in order to optimize our ability to predict and enhance cognitive performance at the individual level.

Furthermore, although we have speculated above on the distinctive neural mechanisms in response to the horror and erotic stimuli, the difficulty in accessing signals directly from deep brain regions such as the amygdala using EEG makes it difficult for us to fully characterize these purported neural pathways underlying emotional processing and attention. A follow-up study using fMRI (functional magnetic resonance imaging) will make it possible to observe activity in deep brain structures in our task.

\section{Conclusion}

Attentional effects of emotional processing may be unavoidable, as the fast and autonomic processing of stimuli may have evolved as an adaptive mechanism for subsequent behaviors. The present study provided a potential explanation for the directional effects of emotion on attention from the perspective of individual differences in emotional processing itself. Remarkably, these individual trends differed according to the category of emotion and were classifiable based on prior electrophysiological responses. These findings may contribute to the development of personalized alerting or cognitive enhancement systems that can not only optimize our performance in everyday life but also help prevent accidents and losses due to inattention. 


\section{References}

Baumgartner, T., Esslen, M., \& Jancke, L. (2006). From emotion perception to emotion experience: Emotions evoked by pictures and classical music. International Journal of Psychophysiology, 60(1), 34-43. https://doi.org/10.1016/j.ijpsycho.2005.04.007

Beck, A. T., Brown, G., Epstein, N., \& Steer, R. A. (1988). An Inventory for Measuring Clinical Anxiety Psychometric Properties. Journal of Consulting and Clinical Psychology, 56(6), 893-897. https://doi.org/10.1037/0022-006x.56.6.893

Beck, A. T., Steer, R. A., \& Brown, G. K. (1996). Manual for the Beck depression inventory-II. San Antonio, TX: Psychological Corporation.

Bocanegra, B. R., \& Zeelenberg, R. (2009). Emotion Improves and Impairs Early Vision. Psychological Science, 20(6), 707-713. https://doi.org/10.1111/j.1467-9280.2009.02354.x

Bocanegra, B. R., \& Zeelenberg, R. (2011). Emotion-Induced Trade-Offs in Spatiotemporal Vision. Journal of Experimental Psychology-General, 140(2), 272-282. https://doi.org/10.1037/a0023188

Bradley, M. M. (2009). Natural selective attention: Orienting and emotion. Psychophysiology, 46(1), 111. https://doi.org/10.1111/j.1469-8986.2008.00702.x

Bradley, M. M., Codispoti, M., Cuthbert, B. N., \& Lang, P. J. (2001). Emotion and Motivation I: Defensive and Appetitive Reactions in Picture Processing. Emotion, 1(3), 276-298. https://doi.org/10.1037//1528-3542.1.3.276

Bradley, M. M., \& Lang, P. J. (1994). Measuring emotion: The self-assessment manikin and the semantic differential. Journal of Behavior Therapy and Experimental Psychiatry, 25(1), 49-59. https://doi.org/10.1016/0005-7916(94)90063-9

Bradley, M. M., \& Lang, P. J. (2000). Measuring emotion: Behavior, feeling, and physiology (Vol. 25).

Brosch, T., Scherer, K. R., Grandjean, D., \& Sander, D. (2013). The impact of emotion on perception, attention, memory, and decision-making. Swiss Medical Weekly, 143. https://doi.org/10.4414/smw.2013.13786

Carretie, L., Hinojosa, J. A., Martin-Loeches, M., Mercado, F., \& Tapia, M. (2004). Automatic attention to emotional stimuli: Neural correlates. Human Brain Mapping, 22(4), 290-299. https://doi.org/10.1002/hbm.20037

Codispoti, M., Ferrari, V., \& Bradley, M. M. (2006). Repetitive picture processing: Autonomic and cortical correlates. Brain Research, 1068(1), 213-220. https://doi.org/10.1016/j.brainres.2005.11.009

Compton, R. J. (2003). The interface between emotion and attention: a review of evidence from psychology and neuroscience. Behavioral Cognitive Neuroscience Reviews, 2(2), 115-129. https://doi.org/10.1177/1534582303255278

Critchley, H. D., Elliott, R., Mathias, C. J., \& Dolan, R. J. (2000). Neural activity relating to generation and representation of galvanic skin conductance responses: A functional magnetic resonance 
imaging study. Journal of Neuroscience, 20(8), 3033-3040. https://doi.org/10.1523/JNEUROSCI.20-08-03033.2000

Cuthbert, B. N., Schupp, H. T., Bradley, M., McManis, M., \& Lang, P. J. (1998). Probing affective pictures: Attended startle and tone probes. Psychophysiology, 35(3), 344-347. https://doi.org/10.1017/S0048577298970536

Cuthbert, B. N., Schupp, H. T., Bradley, M. M., Birbaumer, N., \& Lang, P. J. (2000). Brain potentials in affective picture processing: covariation with autonomic arousal and affective report. Biological Psychology, 52(2), 95-111. https://doi.org/10.1016/S0301-0511(99)00044-7

Delorme, A., \& Makeig, S. (2004). EEGLAB: an open source toolbox for analysis of single-trial EEG dynamics including independent component analysis. Journal of Neuroscience Methods, 134(1), 9-21. https://doi.org/10.1016/j.jneumeth.2003.10.009

Delorme, A., Sejnowski, T., \& Makeig, S. (2007). Enhanced detection of artifacts in EEG data using higherorder statistics and independent component analysis. Neuroimage, 34(4), 1443-1449. https://doi.org/10.1016/j.neuroimage.2006.11.004

Domınguez-Borras, J., \& Vuilleumier, P. (2013). Affective Biases in Attention and Perception.

Eastwood, J. D., Smilek, D., \& Merikle, P. M. (2003). Negative facial expression captures attention and disrupts performance. Perception \& Psychophysics, 65(3), 352-358. https://doi.org/10.3758/Bf03194566

Fan, J., McCandliss, B. D., Fossella, J., Flombaum, J. I., \& Posner, M. I. (2005). The activation of attentional networks. Neuroimage, 26(2), 471-479. https://doi.org/10.1016/j.neuroimage.2005.02.004

Fan, J., McCandliss, B. D., Sommer, T., Raz, A., \& Posner, M. I. (2002). Testing the efficiency and independence of attentional networks. Journal of Cognitive Neuroscience, 14(3), 340-347. https://doi.org/10.1162/089892902317361886

Foti, D., \& Hajcak, G. (2008). Deconstructing reappraisal: Descriptions preceding arousing pictures modulate the subsequent neural response. Journal of Cognitive Neuroscience, 20(6), 977-988. https://doi.org/10.1162/jocn.2008.20066

Friedman, R. S., \& Forster, J. (2010). Implicit Affective Cues and Attentional Tuning: An Integrative Review. Psychological Bulletin, 136(5), 875-893. https://doi.org/10.1037/a0020495

Gohm, C. L., \& Clore, G. L. (2000). Individual differences in emotional experience: Mapping available scales to processes. Personality and Social Psychology Bulletin, 26(6), 679-676. https://doi.org/10.1177/0146167200268004

Hajcak, G., \& Foti, D. (2020). Significance? ... Significance! Empirical, methodological, and theoretical connections between the late positive potential and P300 as neural responses to stimulus significance: An integrative review ... Psychophysiology, 57(7). https://doi.org/10.1111/psyp.13570 
Hajcak, G., MacNamara, A., Foti, D., Ferri, J., \& Keil, A. (2013). The dynamic allocation of attention to emotion: Simultaneous and independent evidence from the late positive potential and steady state visual evoked potentials. Biological Psychology, 92(3), 447-455. https://doi.org/10.1016/j.biopsycho.2011.11.012

Hajcak, G., MacNamara, A., \& Olvet, D. M. (2010). Event-Related Potentials, Emotion, and Emotion Regulation: An Integrative Review. Developmental Neuropsychology, 35(2), 129-155. https://doi.org/10.1080/87565640903526504

Hajcak, G., Weinberg, A., MacNamara, A., \& Foti, D. (2013). ERPs and the Study of Emotion.

Halgren, E. (1992). Emotional neurophysiology of the amygdala within the context of human cognition.

Hamann, S., \& Canli, T. (2004). Individual differences in emotion processing. Current Opinion in Neurobiology, 14(2), 233-238. https://doi.org/10.1016/i.conb.2004.03.010

Ito, T. A., \& Cacioppo, J. T. (2000). Electrophysiological evidence of implicit and explicit categorization processes. Journal of Experimental Social Psychology, 36(6), 660-676. https://doi.org/10.1006/jesp.2000.1430

Johnston, V. S., Miller, D. R., \& Burleson, M. H. (1986). Multiple P3s to Emotional Stimuli and Their Theoretical Significance. Psychophysiology, 23(6), 684-694. https://doi.org/10.1111/j.14698986.1986.tb00694.x

Kolassa, I. T., Musial, F., Mohr, A., Trippe, R. H., \& Miltner, W. H. R. (2005). Electrophysiological correlates of threat processing in spider phobics. Psychophysiology, 42(5), 520-530. https://doi.org/10.1111/j.1469-8986.2005.00315.x

Krolak-Salmon, P., Fischer, C., Vighetto, A., \& Mauguiere, F. (2001). Processing of facial emotional expression: spatio-temporal data as assessed by scalp event-related potentials. European Journal of Neuroscience, 13(5), 987-994. https://doi.org/10.1046/j.0953-816x.2001.01454.x

Lang, P. J., Bradley, M. M., \& Cuthbert, B. N. (1997). Motivated attention: Affect, activation, and action (Vol. 97).

Lang, P. J., Bradley, M. M., \& Cuthbert, B. N. (1998). Emotion, motivation, and anxiety: Brain mechanisms and psychophysiology. Biological Psychiatry, 44(12), 1248-1263. https://doi.org/10.1016/S0006-3223(98)00275-3

Lang, P. J., Greenwald, M. K., Bradley, M. M., \& Hamm, A. O. (1993). Looking at Pictures - Affective, Facial, Visceral, and Behavioral Reactions. Psychophysiology, 30(3), 261-273. https://doi.org/10.1111/j.1469-8986.1993.tb03352.x

Lang, P. J., M., B. M., \& Cuthbert, B. N. (2008). International affective picture system (IAPS): Affective ratings of pictures and instruction manual. Technical Report A-8. University of Florida, Gainesville, FL. 
LeBlanc, V. R., McConnell, M. M., \& Monteiro, S. D. (2015). Predictable chaos: a review of the effects of emotions on attention, memory and decision making. Advances in Health Sciences Education, 20(1), 265-282. https://doi.org/10.1007/s10459-014-9516-6

Leon-Carrion, J., Martin-Rodriguez, J. F., Damas-Lopez, J., Pourrezai, K., Izzetoglu, K., Martin, J. M. B., \& Dominguez-Morales, M. R. (2007). Does dorsolateral prefrontal cortex (DLPFC) activation return to baseline when sexual stimuli cease? The role of DLPFC in visual sexual stimulation. Neuroscience Letters, 416(1), 55-60. https://doi.org/10.1016/j.neulet.2007.01.058

Lin, H. Y., Liang, J. F., Jin, H., \& Zhao, D. M. (2018). Differential effects of uncertainty on LPP responses to emotional events during explicit and implicit anticipation. International Journal of Psychophysiology, 129, 41-51. https://doi.org/10.1016/j.ijpsycho.2018.04.012

Lu, B.-L., Zhang, L., \& Kwok, J. (2011). Neural Information Processing: 18th International Conference, ICONIP 2011, Shanghai, China, November 13-17, 2011, Proceedings, Part III (Vol. 7064). Springer.

Maffei, A., Goertzen, J., Jaspers-Fayer, F., Kleffner, K., Sessa, P., \& Liotti, M. (2021). Spatiotemporal Dynamics of Covert Versus Overt Processing of Happy, Fearful and Sad Facial Expressions. Brain Sciences, 11(7). https://doi.org/10.3390/brainsci11070942

Mardaga, S., Laloyaux, O., \& Hansenne, M. (2006). Personality traits modulate skin conductance response to emotional pictures: An investigation with Cloninger's model of personality. Personality and Individual Differences, 40(8), 1603-1614. https://doi.org/10.1016/i.paid.2005.12.006

Matusz, P. J., Traczyk, J., Sobkow, A., \& Strelau, J. (2015). Individual differences in emotional reactivity moderate the strength of the relationship between attentional and implicit-memory biases towards threat-related stimuli. Journal of Cognitive Psychology, 27(6), 715-724. https://doi.org/10.1080/20445911.2015.1027210

Miltner, W. H. R., Trippe, R. H., Krieschel, S., Gutberlet, I., Hecht, H., \& Weiss, T. (2005). Event-related brain potentials and affective responses to threat in spider/snake-phobic and non-phobic subjects. International Journal of Psychophysiology, 57(1), 43-52. https://doi.org/10.1016/j.ijpsycho.2005.01.012

Mobbs, D., Marchant, J. L., Hassabis, D., Seymour, B., Tan, G., Gray, M., Petrovic, P., Dolan, R. J., \& Frith, C. D. (2009). From Threat to Fear: The Neural Organization of Defensive Fear Systems in Humans. Journal of Neuroscience, 29(39), 12236-12243. https://doi.org/10.1523/Jneurosci.2378-09.2009

Moser, J. S., Most, S. B., \& Simons, R. F. (2010). Increasing negative emotions by reappraisal enhances subsequent cognitive control: a combined behavioral and electrophysiological study. Cognitiv, Affectective, \& Behavioral Neuroscience, 10(2), 195-207. https://doi.org/10.3758/cabn.10.2.195

Naumann, E., Bartussek, D., Diedrich, O., \& Laufer, M. E. (1992). Assessing Cognitive and Affective Information-Processing Functions of the Brain by Means of the Late Positive Complex of the Event-Related Potential. Journal of Psychophysiology, 6(4), 285-298. <Go to ISI>://WOS:A1992KV73700001 
Noble, W. S. (2006). What is a support vector machine? Nature Biotechnology, 24(12), 1565-1567. https://doi.org/10.1038/nbt1206-1565

Northoff, G., Richter, A., Gessner, M., Schlagenhauf, F., Fell, J., Baumgart, F., Kaulisch, T., Kotter, R., Stephan, K. E., Leschinger, A., Hagner, T., Bargel, B., Witzel, T., Hinrichs, H., Bogerts, B., Scheich, H., \& Heinze, H. J. (2000). Functional dissociation between medial and lateral prefrontal cortical spatiotemporal activation in negative and positive emotions: A combined fMRI/MEG study. Cerebral Cortex, 10(1), 93-107. https://doi.org/10.1093/cercor/10.1.93

Olofsson, J. K., Nordin, S., Sequeira, H., \& Polich, J. (2008). Affective picture processing: An integrative review of ERP findings. Biological Psychology, 77(3), 247-265. https://doi.org/10.1016/j.biopsycho.2007.11.006

Ortner, C. N. M., Zelazo, P. D., \& Anderson, A. K. (2013). Effects of emotion regulation on concurrent attentional performance. Motivation and Emotion, 37(2), 346-354. https://doi.org/10.1007/s11031-012-9310-9

Phelps, E. A., Ling, S., \& Carrasco, M. (2006). Emotion facilitates perception and potentiates the perceptual benefits of attention. Psychological Science, 17(4), 292-299. https://doi.org/10.1111/j.1467-9280.2006.01701.x

Pourtois, G., Grandjean, D., Sander, D., \& Vuilleumier, P. (2004). Electrophysiological correlates of rapid spatial orienting towards fearful faces. Cerebral Cortex, 14(6), 619-633. https://doi.org/10.1093/cercor/bhh023

Pourtois, G., Schettino, A., \& Vuilleumier, P. (2013). Brain mechanisms for emotional influences on perception and attention: What is magic and what is not. Biological Psychology, 92(3), 492-512. https://doi.org/10.1016/j.biopsycho.2012.02.007

Prause, N., Janssen, E., \& Hetrick, W. P. (2008). Attention and Emotional Responses to Sexual Stimuli and Their Relationship to Sexual Desire. Archives of Sexual Behavior, 37(6), 934-949. https://doi.org/10.1007/s10508-007-9236-6

Rossignol, M., Philippot, P., Bissot, C., Rigoulot, S., \& Campanella, S. (2012). Electrophysiological correlates of enhanced perceptual processes and attentional capture by emotional faces in social anxiety. Brain Research, 1460, 50-62. https://doi.org/10.1016/j.brainres.2012.04.034

Sabatinelli, D., Lang, P. J., Keil, A., \& Bradley, M. M. (2007). Emotional perception: Correlation of functional MRI and event-related potentials. Cerebral Cortex, 17(5), 1085-1091. https://doi.org/10.1093/cercor/bhl017

Schmeichel, B. J. (2007). Attention control, memory updating, and emotion regulation temporarily reduce the capacity for executive control. Journal of Experimental Psychology-General, 136(2), 241-255. https://doi.org/10.1037/0096-3445.136.2.241

Schupp, H. T., Flaisch, T., Stockburger, J., \& Junghofer, M. (2006). Emotion and attention: event-related brain potential studies. Progress in brain research, 156, 31-51. https://doi.org/10.1016/S0079$\underline{6123(06) 56002-9}$ 
Schupp, H. T., Junghofer, M., Weike, A. I., \& Hamm, A. O. (2003). Emotional facilitation of sensory processing in the visual cortex. Psychological Science, 14(1), 7-13. https://doi.org/10.1111/1467$\underline{9280.01411}$

Schupp, H. T., Stockburger, J., Codispoti, M., Junghofer, M., Weike, A. I., \& Hamm, A. O. (2006). Stimulus novelty and emotion perception: the near absence of habituation in the visual cortex. Neuroreport, 17(4), 365-369. https://doi.org/10.1097/01.wnr.0000203355.88061.c6

Stormark, K. M., Nordby, H., \& Hugdahl, K. (1995). Attentional Shifts to Emotionally Charged Cues Behavioral and Erp Data. Cognition \& Emotion, 9(5), 507-523. https://doi.org/10.1080/02699939508408978

Van Strien, J. W., De Sonneville, L. M. J., \& Franken, I. H. A. (2010). The late positive potential and explicit versus implicit processing of facial valence. Neuroreport, 21(9), 656-661. https://doi.org/10.1097/WNR.0b013e32833ab89e

Vuilleumier, P. (2005). How brains beware: neural mechanisms of emotional attention. Trends in Cognitive Sciences, 9(12), 585-594. https://doi.org/10.1016/j.tics.2005.10.011

Vuilleumier, P., \& Driver, J. (2007). Modulation of visual processing by attention and emotion: windows on causal interactions between human brain regions. Philosophical Transactions of the Royal Society B-Biological Sciences, 362(1481), 837-855. https://doi.org/10.1098/rstb.2007.2092

Wadlinger, H. A., \& Isaacowitz, D. M. (2006). Positive mood broadens visual attention to positive stimuli. Motivation and Emotion, 30(1), 89-101. https://doi.org/10.1007/s11031-006-9021-1

Wiens, S., Sand, A., \& Olofsson, J. K. (2011). Nonemotional features suppress early and enhance late emotional electrocortical responses to negative pictures. Biological Psychology, 86(1), 83-89. https://doi.org/10.1016/i.biopsycho.2010.11.001

Yen, N. S., Chen, K. H., \& Liu, E. H. (2010). Emotional modulation of the late positive potential (LPP) generalizes to Chinese individuals. International Journal of Psychophysiology, 75(3), 319-325. https://doi.org/10.1016/j.ijpsycho.2009.12.014

Zhang, J., \& Zhou, R. L. (2014). Individual Differences in Automatic Emotion Regulation Affect the Asymmetry of the LPP Component. Plos One, 9(2). https://doi.org/10.1371/journal.pone.0088261

Zhao, L., Shi, Z. L., Zheng, Q., Chu, H. D., Xu, L., \& Hu, F. P. (2018). Use of Electroencephalography for the Study of Gain-Loss Asymmetry in Intertemporal Decision-Making. Frontiers in Neuroscience, 12. https://doi.org/10.3389/fnins.2018.00984 
659

660

661

662

663

664

665

666

667

668

669

670

\section{< Figure 1 >}

Figure 1. A. Task sequence. A picture (neutral, positive, erotic, mutilation, or horror) was presented for $80 \mathrm{~ms}$ before the cued Attention Network Task (ANT) to induce emotional processing. When a row of five arrows appeared, participants were asked to indicate the direction of the center arrow (target) as quickly as possible. Reaction time (RT) was measured. B. Examples of horror pictures. A total of 48 horror pictures from a commercially usable free web source were used (other picture categories were taken from the IAPS database). C, D. Comparability of valence (C) and arousal (D) ratings for the nonIAPS Horror pictures. Ten subjects were separately recruited to rate the stimulus set on their valence and arousal. Valence ratings for pictures in the horror category were lower than the ratings for neutral, positive, and erotic pictures but not different from mutilation pictures (C). Arousal ratings for horror pictures were higher than the ratings for neutral pictures but not different from mutilation pictures (D). Black asterisks indicate corrected p-values $<0.05$ for nonparametric paired tests. 
671

672

673

674

675

676

677

678

679

680

681

682

683

684

685

686

\section{< Figure 2 >}

Figure 2. A. Behavioral performance across cue types. RT after the spatial cue was faster than that after the center cue; both were faster than having no cue at all. B. Behavioral performance across target types. RT for the congruent target was faster than RT for the incongruent target. C. SCR difference scores $E_{S C R \text {, emotion }}$ across emotion conditions. Dotted line indicates SCR in the neutral condition. SCR in the horror condition was higher than the neutral condition. D. ERP across emotion conditions after picture presentation in channels Fz, Cz, and Pz. Dotted and colored lines indicate ERPs, with the picture presented at time $=0 \mathrm{~ms}$. P300 and LPP amplitudes were averaged between $250 \mathrm{~ms}$ and $350 \mathrm{~ms}$ and

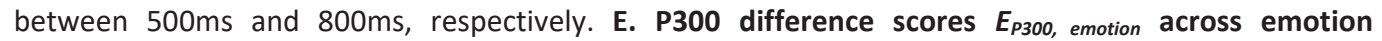
conditions. From the top to bottom, graphs show $E_{P 300, \text { emotion }}$ in channels $F z, C z$, and $P z$. Dotted line indicates P300 in the neutral condition. P300 amplitudes in the horror condition (channel Fz) and erotic condition (channel $\mathrm{Cz}$ ) were higher than the neutral condition. F. LPP difference score $E_{L P P, \text { emotion }}$ across emotion conditions. From the top to bottom, graphs show $E_{L P P, \text { emotion }}$ in channels $\mathrm{Fz}, \mathrm{Cz}$, and $\mathrm{Pz}$. Dotted line indicates LPP in the neutral condition. LPP amplitudes in the erotic condition (channels $\mathrm{Cz}$ and Pz) and horror condition (channel $\mathrm{Pz}$ ) than in the neutral condition. Black asterisks indicate corrected $\mathrm{p}$ values $<0.05$ for paired t-tests or one-sample t-tests. 
687

688

689

690

691

692

693

694

695

696

697

698
< Figure 3 >

Figure 3. A. Individual differences in the direction of emotional effects on RT in the erotic and horror conditions. Dotted line indicates RT in the neutral condition. Each circle signifies individual RT difference scores $E_{R T, \text { emotion }}$ in the erotic and horror conditions. B. Facilitated or impeded group placement. Based on individual emotional effects on $\mathrm{RT}$, the 26 participants were divided into facilitated $\left(E_{R T \text {, emotion }}<0\right)$ and impeded $\left(E_{R T \text {, emotion }}>0\right)$ groups in each of the erotic and horror conditions. Individual group distribution is visualized using different shading. C, D. Topographical maps of ERP difference scores in the erotic condition (C) and horror condition (D). Black asterisks indicate that ERP amplitude in the erotic or horror condition was higher than the neutral condition. Top two topographic maps show $E_{P 300, \text { erotic }}(\mathrm{C})$ and $E_{P 300, \text { horror }}(D)$ and bottom maps show $E_{L P P, \text { erotic }}(C)$ and $E_{L P P, \text { horror }}(D)$. Topographic maps in each left side were from people whose attention was facilitated and maps in each right side were from those whose attention was impeded. 
699

700

701

702

703

704

705

706

707

708

709

710

711

712

713

714

\section{< Figure 4 >}

Figure 4. A. Task sequence. In the first part, an independent sample of 17 participants were asked to report their experience and awareness of the briefly-presented pictures after each trial of the task (60 trials total, 12 per picture category). Participants rated their perceived level of awareness of the presented picture after each trial. In the second part, half of the previously presented pictures and novel lure pictures in the same category were presented one by one as a recognition task in which subjects answered whether they had seen the picture in the first part. B. Subjective awareness. 0: Not aware, 25: Color only, 50: Emotional feeling, 75: Detailed recognition, and 100: Perfect recognition. C. Comparison of reported and actual effects of the pictures on attention. In the erotic and horror conditions, participants were also asked about how they felt their reaction time was influenced by the pictures (facilitated vs. impeded). Their responses are shown alongside the actual attentional effects using different-colored shading; there was no significant correspondence between the two, meaning that participants were not aware of the effect that the pictures had on their subsequent attention. D. Recognition memory accuracy. Participants were not able to distinguish the pictures they saw from lures in the same category, suggesting that while they were aware of the picture being flashed, they failed to process them in detail. 
Table 1. Statistical table 1

\begin{tabular}{|c|c|c|c|c|c|c|c|}
\hline$\#$ & Figure & Description & Data structure & Type of test & Statistical values & Significance & Effect size \\
\hline 1 & 1D-left & valence & $\begin{array}{c}\text { normality not } \\
\text { assumed }\end{array}$ & one-way Friedman's test & $X^{2}=38.000$ & $p<0.001$ & - \\
\hline 2 & 1D-left & valence (neu vs. pos) & $\begin{array}{c}\text { normality not } \\
\text { assumed }\end{array}$ & $\begin{array}{c}\text { post-hoc Wilcoxon signed rank } \\
\text { test }\end{array}$ & $Z=-2.803$ & $p$ corrected $=0.051$ & $r=-0.886$ \\
\hline 3 & & valence (neu vs. ero) & & & $Z=-2.803$ & $p$ corrected $=0.051$ & $r=-0.886$ \\
\hline 4 & & valence (neu vs. mut) & & & $Z=2.803$ & p corrected $=0.046$ & $r=0.886$ \\
\hline 5 & & valence (neu vs. hor) & & & $Z=2.803$ & $p$ corrected $=0.041$ & $r=0.886$ \\
\hline 6 & & valence (pos vs. ero) & & & $Z=1.886$ & $p$ corrected $=0.119$ & $r=0.596$ \\
\hline 7 & & valence (pos vs. mut) & & & $Z=2.803$ & p corrected $=0.035$ & $r=0.886$ \\
\hline 8 & & valence (pos vs. hor) & & & $Z=2.803$ & $p$ corrected $=0.030$ & $r=0.886$ \\
\hline 9 & & valence (ero vs. mut) & & & $Z=2.803$ & $p$ corrected $=0.025$ & $r=0.886$ \\
\hline 10 & & valence (ero vs. hor) & & & $Z=2.803$ & $p$ corrected $=0.020$ & $r=0.886$ \\
\hline 11 & & valence (mut vs. hor) & & & $Z=-1.580$ & $p$ corrected $=0.119$ & $r=-0.500$ \\
\hline 12 & 1D-right & arousal & $\begin{array}{c}\text { normality not } \\
\text { assumed }\end{array}$ & one-way Friedman's test & $x^{2}=29.760$ & $p<0.001$ & - \\
\hline 13 & 1D-right & arousal (neu vs. pos) & $\begin{array}{c}\text { normality not } \\
\text { assumed }\end{array}$ & $\begin{array}{c}\text { post-hoc Wilcoxon signed rank } \\
\text { test }\end{array}$ & $Z=-2.803$ & $p$ corrected $=0.051$ & $r=-0.886$ \\
\hline 14 & & arousal (neu vs. ero) & & & $Z=-2.803$ & $p$ corrected $=0.051$ & $r=-0.886$ \\
\hline 15 & & arousal (neu vs. mut) & & & $Z=-2.803$ & $p$ corrected $=0.046$ & $r=-0.886$ \\
\hline 16 & & arousal (neu vs. hor) & & & $Z=-2.803$ & $p$ corrected $=0.041$ & $r=-0.886$ \\
\hline 17 & & arousal (pos vs. ero) & & & $Z=-2.192$ & $p$ corrected $=0.124$ & $r=-0.693$ \\
\hline 18 & & arousal (pos vs. mut) & & & $Z=-2.497$ & $p$ corrected $=0.075$ & $r=-0.790$ \\
\hline 19 & & arousal (pos vs. hor) & & & $Z=-2.244$ & $p$ corrected $=0.124$ & $r=-0.710$ \\
\hline 20 & & arousal (ero vs. mut) & & & $Z=-1.478$ & $p$ corrected $=0.418$ & $r=-0.467$ \\
\hline 21 & & arousal (ero vs. hor) & & & $Z=-1.172$ & $p$ corrected $=0.482$ & $r=-0.371$ \\
\hline 22 & & arousal (mut vs. hor) & & & $Z=0.459$ & p corrected $=0.647$ & $r=0.145$ \\
\hline
\end{tabular}


Table 2. Statistical table 2

\begin{tabular}{|c|c|c|c|c|c|c|c|}
\hline$\#$ & Figure & Description & Data structure & Type of test & Statistical values & Significance & Effect size \\
\hline 1 & $2 A, B$ & RT (cue) & assumed normal & $\begin{array}{l}\text { three-way repeated measures } \\
\text { ANOVA }\end{array}$ & $\begin{array}{c}F(1.601,48.025)= \\
49.605\end{array}$ & $p<0.001$ & $n_{p}^{2}=0.213$ \\
\hline 2 & & RT (target) & & & $F(1,30)=8.109$ & $p=0.008$ & $\eta_{p}^{2}=0.623$ \\
\hline 3 & & $\mathrm{RT}$ (emotion) & & & $F(4,120)=2.839$ & $p=0.027$ & $\eta_{p}^{2}=0.086$ \\
\hline 4 & & RT (cue * target) & & & $F(1.654,49.629)=1.756$ & $p=0.188$ & $\eta_{p}^{2}=0.055$ \\
\hline 5 & & RT (cue * emotion) & & & $F(8,240)=0.843$ & $p=0.565$ & $\eta_{p}^{2}=0.027$ \\
\hline 6 & & RT (target * emotion) & & & $F(4,120)=1.405$ & $p=0.237$ & $\eta_{p}^{2}=0.045$ \\
\hline 7 & & RT (cue * target * emotion) & & & $\begin{array}{c}\mathrm{F}(5.774,173.213)= \\
0.873\end{array}$ & $p=0.513$ & $\eta_{p}^{2}=0.028$ \\
\hline 8 & $2 \mathrm{~A}$ & cue (no vs. center) & assumed normal & post-hoc pairwise t-test & $t(30)=4.517$ & p corrected $<0.001$ & $d=0.811$ \\
\hline 9 & & cue (no vs. spatial) & & & $t(30)=8.659$ & p corrected $<0.001$ & $d=1.555$ \\
\hline 10 & & cue (center vs. spatial) & & & $t(30)=5.871$ & p corrected $<0.001$ & $d=1.054$ \\
\hline 11 & $2 B$ & $\begin{array}{l}\text { target (congruent vs. } \\
\text { incongruent) }\end{array}$ & assumed normal & post-hoc pairwise t-test & $t(30)=-2.826$ & $p=0.008$ & $d=-0.508$ \\
\hline 12 & - & $\mathrm{E}_{\mathrm{RT} \text {, pos }}$ & assumed normal & one-sample t-test & $t(30)=-1.985$ & $\mathrm{p}$ corrected $=0.169$ & $d=-0.356$ \\
\hline 13 & & $E_{R T \text {, ero }}$ & & & $t(30)=-1.836$ & $p$ corrected $=0.169$ & $d=-0.330$ \\
\hline 14 & & $\mathrm{E}_{\mathrm{RT} \text {, mut }}$ & & & $t(30)=-2.216$ & $\mathrm{p}$ corrected $=0.138$ & $d=-0.398$ \\
\hline 15 & & $\mathrm{E}_{\mathrm{RT} \text {, hor }}$ & & & $t(30)=-0.348$ & $p$ corrected $=0.730$ & $d=-0.063$ \\
\hline 16 & - & $\mathrm{E}_{\mathrm{RT} \text {, emotion }}$ & assumed normal & $\begin{array}{c}\text { one-way repeated measures } \\
\text { ANOVA }\end{array}$ & $F(3,90)=2.546$ & $p=0.061$ & $\eta_{p}^{2}=0.078$ \\
\hline 17 & $2 \mathrm{C}$ & $E_{S C R \text {, pos }}$ & assumed normal & one-sample t-test & $t(30)=-0.261$ & $\mathrm{p}$ corrected $=0.796$ & $d=-0.047$ \\
\hline 18 & & $\mathrm{E}_{\mathrm{SCR} \text {, ero }}$ & & & $t(30)=-1.087$ & $p$ corrected $=0.857$ & $d=-0.195$ \\
\hline 19 & & $\mathrm{E}_{S C R, \text { mut }}$ & & & $\mathrm{t}(30)=1.007$ & $\mathrm{p}$ corrected $=0.857$ & $d=0.181$ \\
\hline 20 & & $\mathrm{E}_{\mathrm{SCR} \text {, hor }}$ & & & $t(30)=2.675$ & $p$ corrected $=0.048$ & $d=0.481$ \\
\hline 21 & $2 \mathrm{C}$ & $\mathrm{E}_{\mathrm{SCR} \text {, emotion }}$ & assumed normal & $\begin{array}{c}\text { one-way repeated measures } \\
\text { ANOVA }\end{array}$ & $F(3,90)=4.955$ & $p=0.003$ & $n_{p}^{2}=0.142$ \\
\hline 22 & $2 \mathrm{C}$ & $\mathrm{E}_{\mathrm{SCR}, \text { emotion }}$ (pos vs hor) & assumed normal & post-hoc pairwise t-test & $t(30)=-2.813$ & $p$ corrected $=0.043$ & $d=-0.505$ \\
\hline 23 & & $E_{S C R \text {, emotion (ero vs hor) }}$ & & & $t(30)=-3.377$ & $\mathrm{p}$ corrected $=0.012$ & $d=-0.607$ \\
\hline 24 & 2E-top & $\mathrm{E}_{\mathrm{P} 300, \text { pos }}$ in $\mathrm{Fz}$ & assumed normal & one-sample t-test & $t(25)=0.792$ & $\mathrm{p}$ corrected $=0.871$ & $d=0.154$ \\
\hline 25 & & $\mathrm{E}_{\mathrm{P} 300 \text {, ero }}$ in $\mathrm{Fz}$ & & & $t(25)=2.4981$ & $\mathrm{p}$ corrected $=0.058$ & $d=0.490$ \\
\hline 26 & & $\mathrm{E}_{\mathrm{p} 300, \mathrm{mut}}$ in $\mathrm{Fz}$ & & & $t(25)=-0.586$ & $\mathrm{p}$ corrected $=0.871$ & $d=-0.115$ \\
\hline 27 & & $\mathrm{E}_{\mathrm{P} 300, \text { hor }}$ in $\mathrm{Fz}$ & & & $t(25)=3.387$ & $p$ corrected $=0.009$ & $d=0.664$ \\
\hline 28 & 2E-mid & $\mathrm{E}_{\mathrm{P} 300, \text { pos }}$ in $\mathrm{Cz}$ & assumed normal & one-sample t-test & $t(25)=-0.102$ & $\mathrm{p}$ corrected $=0.919$ & $d=-0.020$ \\
\hline 29 & & $E_{P 300, \text { ero }}$ in $C z$ & & & $\mathrm{t}(25)=2.923$ & $\mathrm{p}$ corrected $=0.029$ & $d=0.573$ \\
\hline 30 & & $\mathrm{E}_{\mathrm{P} 300, \text { mut }}$ in $\mathrm{Cz}$ & & & $t(25)=-1.807$ & $p$ corrected $=0.249$ & $d=-0.354$ \\
\hline 31 & & $\mathrm{E}_{\mathrm{P} 300, \text { hor }}$ in $\mathrm{Cz}$ & & & $t(25)=1.342$ & $p$ corrected $=0.383$ & $d=0.263$ \\
\hline 32 & 2E-botom & $\mathrm{E}_{\mathrm{P} 300, \text { pos }}$ in $\mathrm{Pz}$ & assumed normal & one-sample t-test & $t(25)=-0.583$ & p corrected $=1$ & $d=-0.115$ \\
\hline 33 & & $\mathrm{E}_{\mathrm{P} 300, \text { ero }}$ in $\mathrm{Pz}$ & & & $t(25)=0.064$ & $\mathrm{p}$ corrected $=1$ & $d=0.013$ \\
\hline 34 & & $\mathrm{E}_{\mathrm{P} 300, \text { mut }}$ in $\mathrm{Pz}$ & & & $t(25)=-1.436$ & $p$ corrected $=0.653$ & $\mathrm{~d}=-0.282$ \\
\hline 35 & & $\mathrm{E}_{\mathrm{P} 300, \text { hor }}$ in $\mathrm{Pz}$ & & & $t(25)=0.806$ & p corrected $=1$ & $d=0.158$ \\
\hline 36 & $2 \mathrm{E}$ & $\mathrm{E}_{\mathrm{P} 300, \text { emotion (channel) }}$ & assumed normal & $\begin{array}{c}\text { two-way repeated measures } \\
\text { ANOVA }\end{array}$ & $F(1.568,39.193)=1.757$ & $p=0.191$ & $n_{p}^{2}=0.066$ \\
\hline 37 & & $\mathrm{E}_{\mathrm{p} 300, \text { emotion }}$ (emotion) & & & $F(3,75)=9.065$ & $p<0.001$ & $\eta_{p}^{2}=0.266$ \\
\hline
\end{tabular}




\begin{tabular}{|c|c|c|c|c|c|c|c|}
\hline 38 & & $\begin{array}{c}E_{p 300, \text { emotion }} \\
\text { (channel * emotion) }\end{array}$ & & & $F(6,150)=0.958$ & $p=0.456$ & $\eta_{p}^{2}=0.037$ \\
\hline 39 & $2 \mathrm{E}$ & $\mathrm{E}_{\mathrm{P} 300, \text { emotion }}$ (pos vs ero) & assumed normal & post-hoc pairwise t-test & $t(25)=-2.926$ & $p$ corrected $=0.029$ & $d=-0.574$ \\
\hline 40 & & $E_{p 300, \text { emotion (ero vs mut) }}$ & & & $t(25)=4.349$ & $p$ corrected $=0.001$ & $d=0.853$ \\
\hline 41 & & $\mathrm{E}_{\mathrm{p} 300, \text { emotion }}$ (mut vs hor) & & & $t(25)=-4.074$ & p corrected $=0.002$ & $d=-0.799$ \\
\hline 42 & 2-F-top & $\mathrm{E}_{\mathrm{LPP}, \text { pos }}$ in $\mathrm{Fz}$ & assumed normal & one-sample t-test & $t(25)=0.099$ & p corrected $=0.922$ & $d=0.019$ \\
\hline 43 & & $E_{L P p, \text { ero }}$ in $F z$ & & & $t(25)=-1.255$ & $p$ corrected $=0.885$ & $d=-0.246$ \\
\hline 44 & & $\mathrm{E}_{\mathrm{LPP}, \mathrm{mut}}$ in $\mathrm{Fz}$ & & & $t(25)=-0.992$ & $p$ corrected $=0.961$ & $d=-0.195$ \\
\hline 45 & & $\mathrm{E}_{\mathrm{LPP}, \text { hor }}$ in $\mathrm{Fz}$ & & & $t(25)=-1.014$ & $p$ corrected $=0.961$ & $d=-0.199$ \\
\hline 46 & $2 \mathrm{~F}-\mathrm{mid}$ & $\mathrm{E}_{\mathrm{LPP}, \text { pos }}$ in $\mathrm{Cz}$ & assumed normal & one-sample t-test & $t(25)=-0.180$ & p corrected $=0.859$ & $d=-0.035$ \\
\hline 47 & & $\mathrm{E}_{\mathrm{LPP} \text {, ero }}$ in $\mathrm{Cz}$ & & & $t(25)=5.924$ & p corrected $<0.001$ & $d=1.162$ \\
\hline 48 & & $\mathrm{E}_{L P P, \text { mut }}$ in $\mathrm{Cz}$ & & & $t(25)=1.926$ & p corrected $=0.131$ & $d=0.378$ \\
\hline 49 & & $\mathrm{E}_{\mathrm{LPP} \text {, hor }}$ in $\mathrm{Cz}$ & & & $\mathrm{t}(25)=2.436$ & $p$ corrected $=0.067$ & $d=0.478$ \\
\hline 50 & 2F-botom & $\mathrm{E}_{\mathrm{LPP}, \mathrm{pos}}$ in $\mathrm{Pz}$ & assumed normal & one-sample t-test & $t(25)=2.436$ & $p$ corrected $=0.847$ & $d=0.038$ \\
\hline 51 & & $\mathrm{E}_{L P P, \text { ero }}$ in $\mathrm{Pz}$ & & & $t(25)=6.708$ & p corrected $<0.001$ & $d=1.316$ \\
\hline 52 & & $\mathrm{E}_{\mathrm{LPP}, \text { mut }}$ in $\mathrm{Pz}$ & & & $t(25)=2.150$ & $p$ corrected $=0.083$ & $d=0.422$ \\
\hline 53 & & $\mathrm{E}_{\mathrm{LPP}, \text { hor }}$ in $\mathrm{Pz}$ & & & $t(25)=3.258$ & $p$ corrected $=0.010$ & $d=0.639$ \\
\hline 54 & $2 \mathrm{~F}$ & $\mathrm{E}_{\mathrm{LPP} \text {, emotion (channel) }}$ & assumed normal & $\begin{array}{l}\text { two-way repeated measures } \\
\text { ANOVA }\end{array}$ & $F(1.164,27.937)=7.019$ & $p=0.010$ & $\eta_{p}^{2}=0.226$ \\
\hline 55 & & $\mathrm{E}_{\mathrm{LPP}, \text { emotion }}$ (emotion) & & & $F(3,72)=5.598$ & $p=0.002$ & $n_{p}{ }^{2}=0.189$ \\
\hline 56 & & $\begin{array}{c}\mathrm{E}_{\text {LPP, emotion }} \\
\text { (channel * emotion) }\end{array}$ & & & $F(2.753,66.070)=3.998$ & $p=0.013$ & $n_{p}^{2}=0.143$ \\
\hline 57 & $2 \mathrm{~F}-\mathrm{mid}$ & $\begin{array}{c}\mathrm{E}_{\text {LPp, emotion }} \\
\text { (pos vs ero) in Cz }\end{array}$ & assumed normal & post-hoc pairwise t-test & $t(25)=-5.407$ & p corrected $<0.001$ & $d=-1.060$ \\
\hline 58 & & $\begin{array}{c}\mathrm{E}_{\text {LPp, emotion }} \\
\text { (pos vs hor) in Cz }\end{array}$ & & & $t(25)=-2.888$ & p corrected $=0.040$ & $d=-0.566$ \\
\hline 59 & 2F-bottom & $\begin{array}{c}\mathrm{E}_{\text {LPP, emotion }} \\
\text { (pos vs ero) in Pz }\end{array}$ & assumed normal & post-hoc pairwise t-test & $t(25)=-5.735$ & p corrected $<0.001$ & $d=-1.125$ \\
\hline 60 & & $\mathrm{E}_{\mathrm{LPP} \text {, emotion (pos vs hor) in } \mathrm{Pz}}$ & & & $t(25)=-2.940$ & $p$ corrected $=0.035$ & $d=-0.577$ \\
\hline 61 & 3C-top left & $\mathrm{E}_{\mathrm{P} 300, \text { ero }}$ in $\mathrm{Fz}$ & $\begin{array}{c}\text { normality not } \\
\text { assumed }\end{array}$ & $\begin{array}{l}\text { one-sample Wilcoxon signed } \\
\text { rank test }\end{array}$ & $Z=1.782$ & p corrected $=0.075$ & $r=0.494$ \\
\hline 62 & & $E_{p 300, \text { ero in } \mathrm{Cz}}$ & & & $Z=-0.035$ & $p$ corrected $=0.972$ & $r=-0.010$ \\
\hline 63 & & $E_{P 300, \text { ero }}$ in $\mathrm{Pz}$ & & & $Z=0.315$ & p corrected $=1$ & $r=0.087$ \\
\hline 64 & 3C-top right & $\mathrm{E}_{\mathrm{P} 300 \text {, ero in } \mathrm{Fz}}$ & $\begin{array}{c}\text { normality not } \\
\text { assumed }\end{array}$ & $\begin{array}{l}\text { one-sample Wilcoxon signed } \\
\text { rank test }\end{array}$ & $Z=2.551$ & $\mathrm{p}$ corrected $=0.022$ & $r=0.708$ \\
\hline 65 & & $E_{P 300, \text { ero in }} \mathrm{Cz}$ & & & $Z=3.180$ & p corrected $=0.003$ & $r=0.882$ \\
\hline 66 & & $\mathrm{E}_{\mathrm{P} 300, \text { ero }}$ in $\mathrm{Pz}$ & & & $Z=0.315$ & $\mathrm{p}$ corrected $=1$ & $r=0.087$ \\
\hline 67 & $\begin{array}{c}\text { 3C-bottom } \\
\text { left }\end{array}$ & $\mathrm{E}_{\mathrm{LPP} \text {, ero }}$ in $\mathrm{Fz}$ & $\begin{array}{c}\text { normality not } \\
\text { assumed }\end{array}$ & $\begin{array}{l}\text { one-sample Wilcoxon signed } \\
\text { rank test }\end{array}$ & $Z=0.245$ & $p$ corrected $=0.807$ & $r=0.068$ \\
\hline 68 & & $\mathrm{E}_{\mathrm{LPP} \text {, ero }}$ in $\mathrm{Cz}$ & & & $Z=2.551$ & p corrected $=0.011$ & $r=0.708$ \\
\hline 69 & & $\mathrm{E}_{\mathrm{LP} \text {, ero }}$ in $\mathrm{Pz}$ & & & $Z=3.110$ & $p$ corrected $=0.003$ & $r=0.863$ \\
\hline 70 & $\begin{array}{c}\text { 3C-bottom } \\
\text { right }\end{array}$ & $E_{L P p}$, ero in $F z$ & $\begin{array}{c}\text { normality not } \\
\text { assumed }\end{array}$ & $\begin{array}{l}\text { one-sample Wilcoxon signed } \\
\text { rank test }\end{array}$ & $Z=-1.223$ & $p$ corrected $=0.443$ & $r=-0.339$ \\
\hline 71 & & $\mathrm{E}_{\mathrm{LP}, \text { ero }}$ in $\mathrm{Cz}$ & & & $Z=3.110$ & p corrected $=0.003$ & $r=0.863$ \\
\hline 72 & & $\mathrm{E}_{\mathrm{LPP}, \text { ero }}$ in $\mathrm{Pz}$ & & & $Z=3.040$ & p corrected $=0.003$ & $r=0.843$ \\
\hline 73 & 3D-top left & $\mathrm{E}_{\mathrm{P} 300, \text { hor }}$ in $\mathrm{Fz}$ & $\begin{array}{c}\text { normality not } \\
\text { assumed }\end{array}$ & $\begin{array}{l}\text { one-sample Wilcoxon signed } \\
\text { rank test }\end{array}$ & $Z=2.341$ & $\mathrm{p}$ corrected $=0.038$ & $r=0.649$ \\
\hline 74 & & $\mathrm{E}_{\mathrm{P} 300, \text { hor in } \mathrm{Cz}}$ & & & $Z=0.944$ & p corrected $=0.691$ & $r=0.262$ \\
\hline 75 & & $\mathrm{E}_{\mathrm{P} 300, \text { hor }}$ in $\mathrm{Pz}$ & & & $Z=1.572$ & $p$ corrected $=0.232$ & $r=0.436$ \\
\hline
\end{tabular}




\begin{tabular}{|c|c|c|c|c|c|c|c|}
\hline 76 & $3 \mathrm{D}$-top right & $\mathrm{E}_{\mathrm{P} 300, \text { hor in }} \mathrm{Fz}$ & $\begin{array}{c}\text { normality not } \\
\text { assumed }\end{array}$ & $\begin{array}{l}\text { one-sample Wilcoxon signed } \\
\text { rank test }\end{array}$ & $\mathrm{Z}=1.852$ & p corrected $=0.064$ & $r=0.514$ \\
\hline 77 & & $\mathrm{E}_{\mathrm{P} 300, \text { hor }}$ in $\mathrm{Cz}$ & & & $z=0.804$ & p corrected $=0.691$ & $r=0.223$ \\
\hline 78 & & $\mathrm{E}_{\mathrm{P} 300, \text { hor }}$ in $\mathrm{Pz}$ & & & $Z=-1.223$ & p corrected $=0.232$ & $r=-0.339$ \\
\hline 79 & $\begin{array}{c}\text { 3D-bottom } \\
\text { left }\end{array}$ & $\mathrm{E}_{\mathrm{LPP}, \text { hor }}$ in $\mathrm{Fz}$ & $\begin{array}{c}\text { normality not } \\
\text { assumed }\end{array}$ & $\begin{array}{l}\text { one-sample Wilcoxon signed } \\
\text { rank test }\end{array}$ & $z=0.175$ & $p$ corrected $=0.861$ & $r=0.049$ \\
\hline 80 & & $\mathrm{E}_{\mathrm{LPP}, \text { hor }}$ in $\mathrm{Cz}$ & & & $\mathrm{z}=1.712$ & p corrected $=0.174$ & $r=0.475$ \\
\hline 81 & & $\mathrm{E}_{\mathrm{LPP}, \text { hor }}$ in $\mathrm{Pz}$ & & & $z=2.271$ & $p$ corrected $=0.046$ & $r=0.630$ \\
\hline 82 & $\begin{array}{c}\text { 3D-bottom } \\
\text { right }\end{array}$ & $\mathrm{E}_{\mathrm{LPP}, \text { hor }}$ in $\mathrm{Fz}$ & $\begin{array}{c}\text { normality not } \\
\text { assumed }\end{array}$ & $\begin{array}{l}\text { one-sample Wilcoxon signed } \\
\text { rank test }\end{array}$ & $z=-1.503$ & $p$ corrected $=0.266$ & $r=-0.417$ \\
\hline 83 & & $\mathrm{E}_{\mathrm{LPP}, \text { hor }}$ in $\mathrm{Cz}$ & & & $z=1.503$ & $p$ corrected $=0.174$ & $r=0.417$ \\
\hline 84 & & $\mathrm{E}_{\text {LPP, hor }}$ in Pz & & & $z=1.852$ & $p$ corrected $=0.064$ & $r=0.514$ \\
\hline
\end{tabular}

718 
Table 3. Unimodal and multimodal classification accuracy and AUC across emotion conditions.

\begin{tabular}{|c|c|c|c|}
\hline Feature modality & Emotion & \% Accuracy (SE) & AUC (SE) \\
\hline Unimodal & positive & $53.0(6.146)$ & $0.631(0.005)$ \\
\hline & erotic & $66.0(4.947)$ & $0.761(0.006)$ \\
\hline & mutilation & $51.3(6.125)$ & $0.480(0.046)$ \\
\hline & horror & $65.5(6.799)$ & $0.762(0.012)$ \\
\hline & positive & $56.2(3.686)$ & $0.686(0.008)$ \\
\hline Multimodal & erotic & $70.5(4.269)$ & $0.742(0.012)$ \\
\hline & mutilation & $51.0(6.902)$ & $0.452(0.047)$ \\
\hline & horror & $73.5(5.438)$ & $0.817(0.009)$ \\
\hline
\end{tabular}

SE: Standard error; AUC: Area under the ROC curve 
A
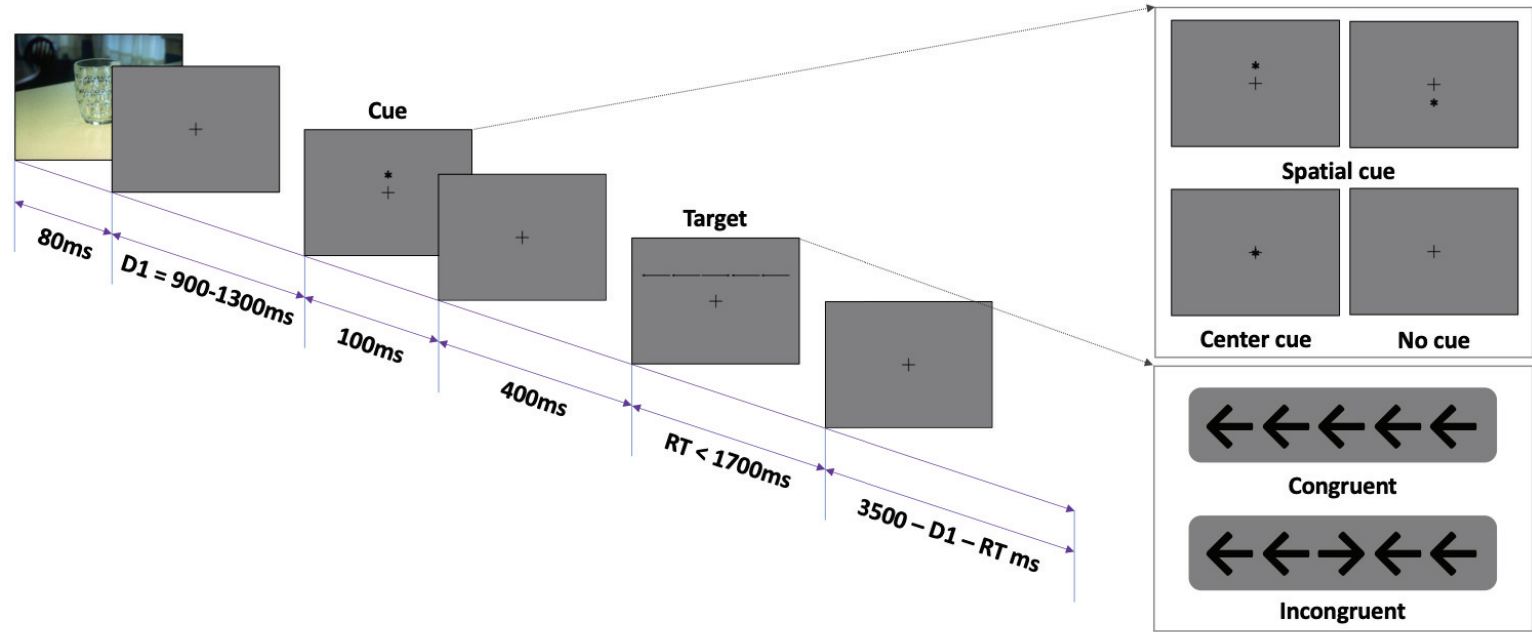

B
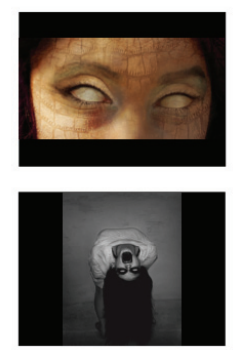
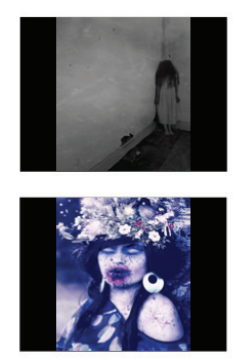
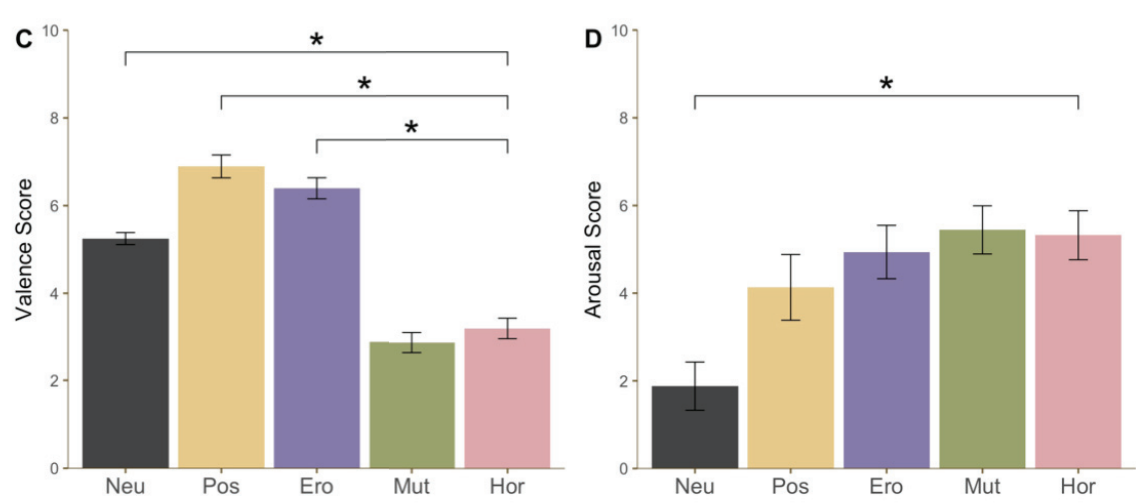

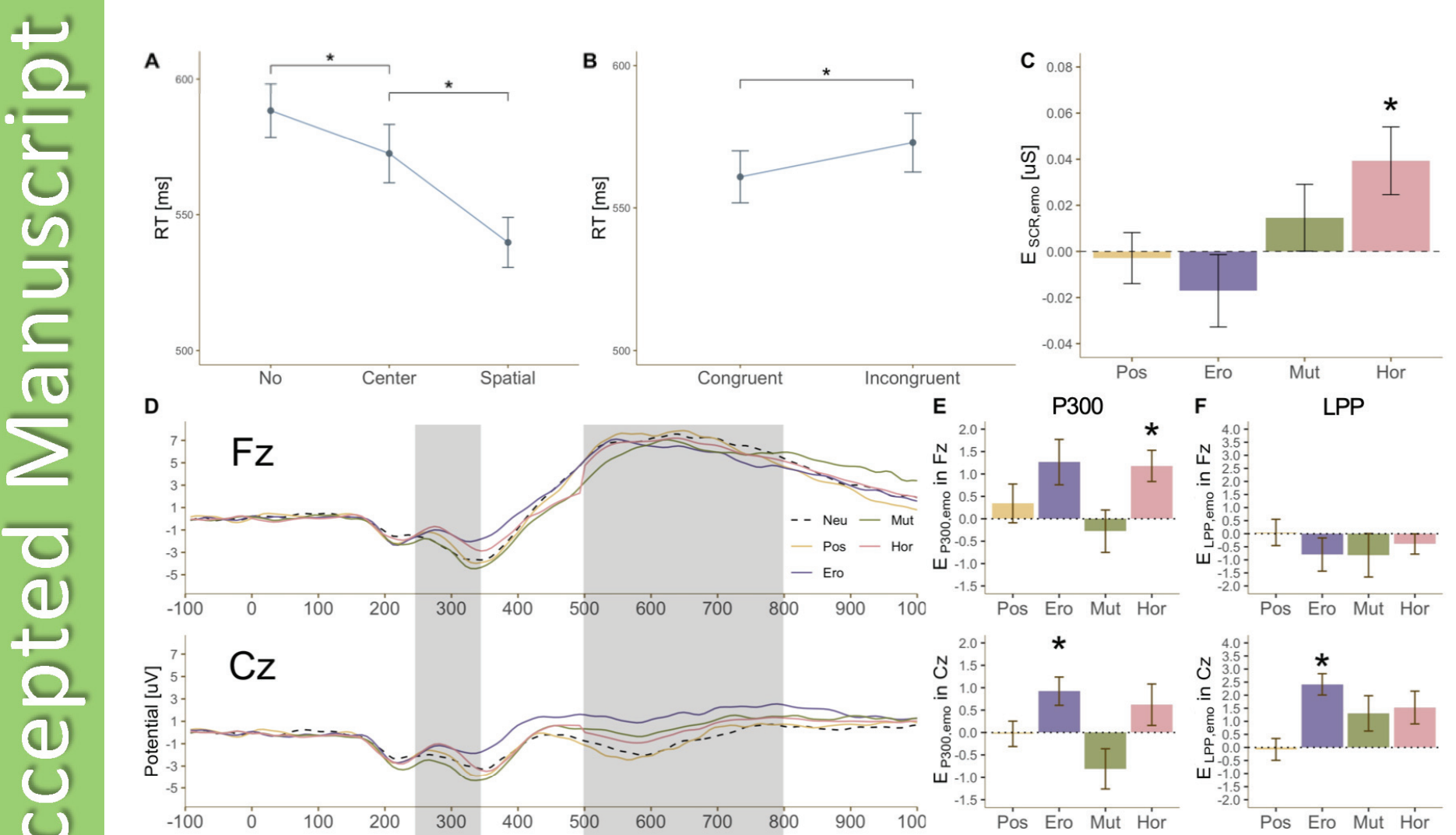

2.0

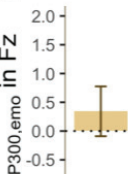

P300

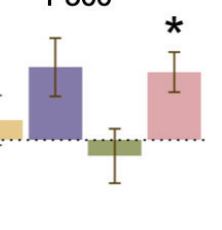

$\mathrm{F}$

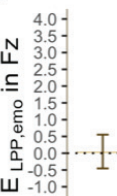

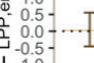

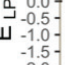

III Pos Éro Mut Hor

\begin{tabular}{rr} 
& 3.0 \\
$\subseteq$ & 2.5 \\
\hdashline & 0. \\
0 & 1.5
\end{tabular}

\begin{tabular}{rr} 
& 2.0 \\
0 & 1.5 \\
0 & 1.0 \\
\hline & 0.5
\end{tabular}

o. 0.5 . $0 . .5$.

-1.5
-1.5
-1.5

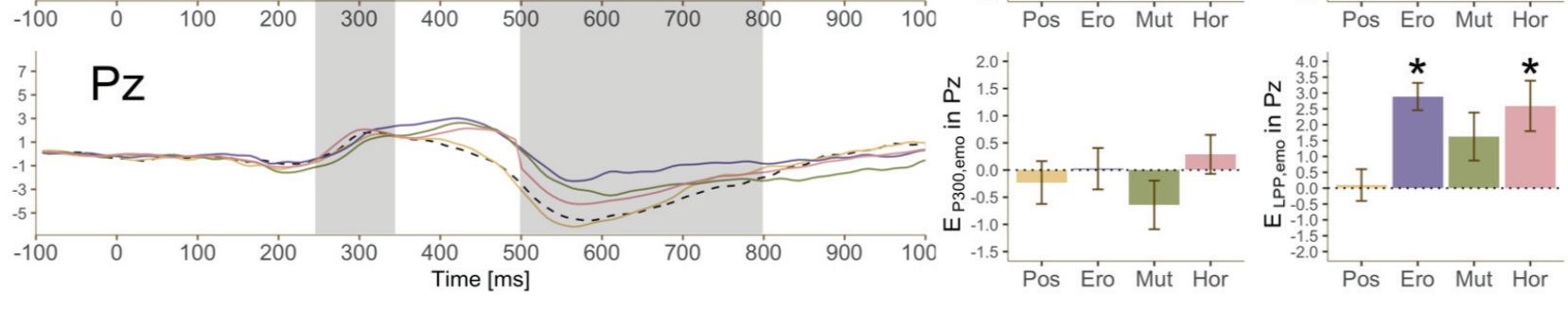



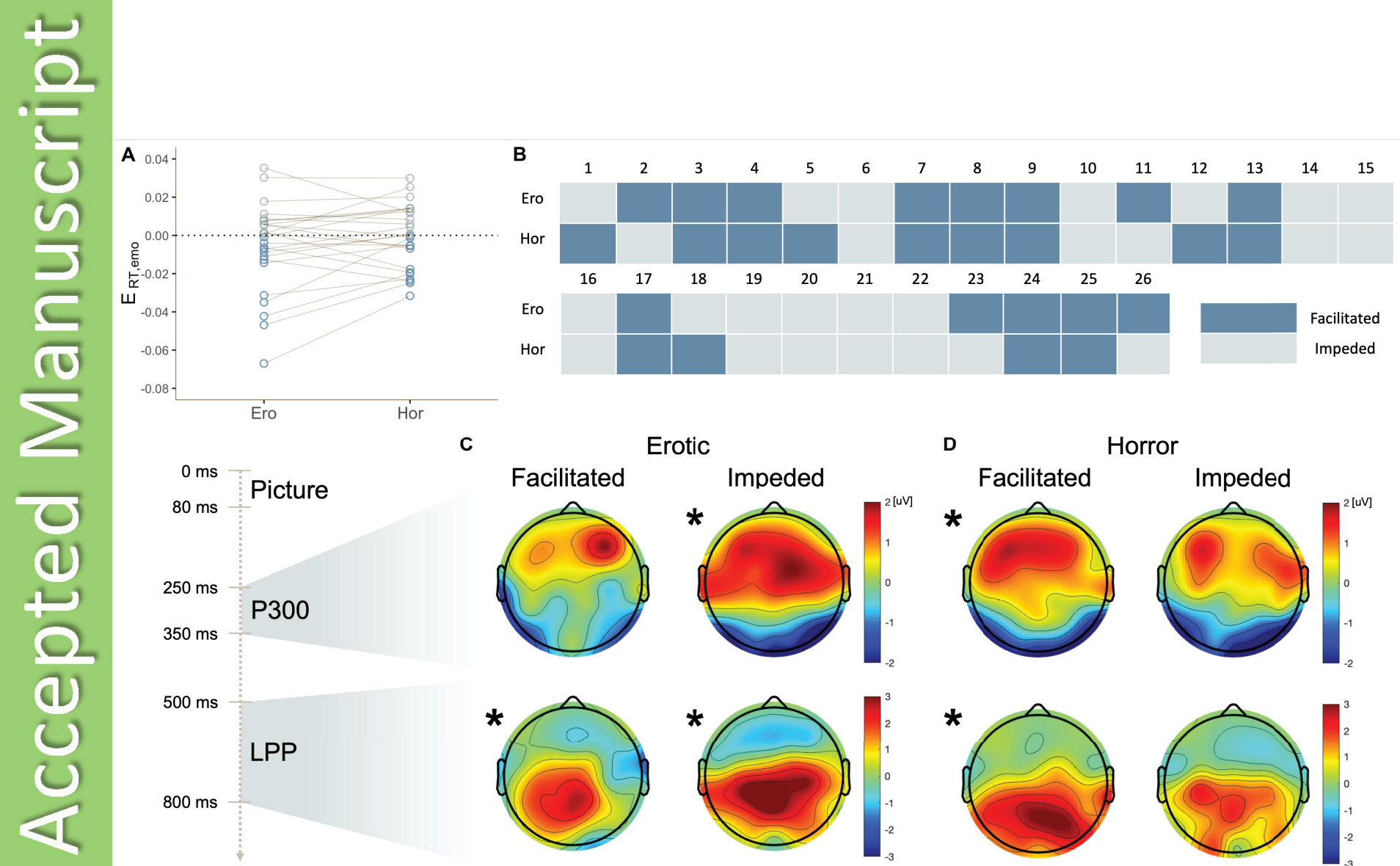

Erotic

D Horror
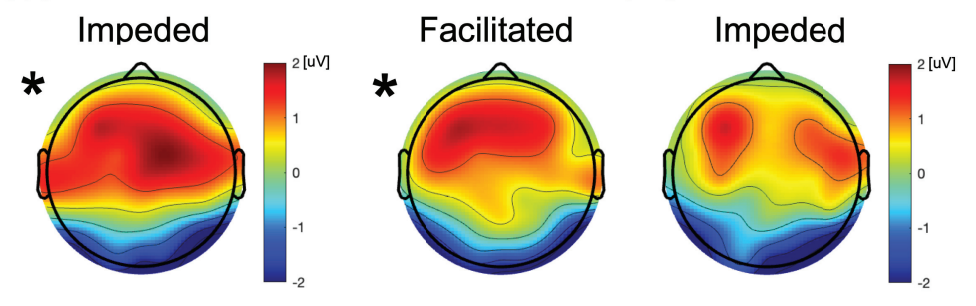

(2)
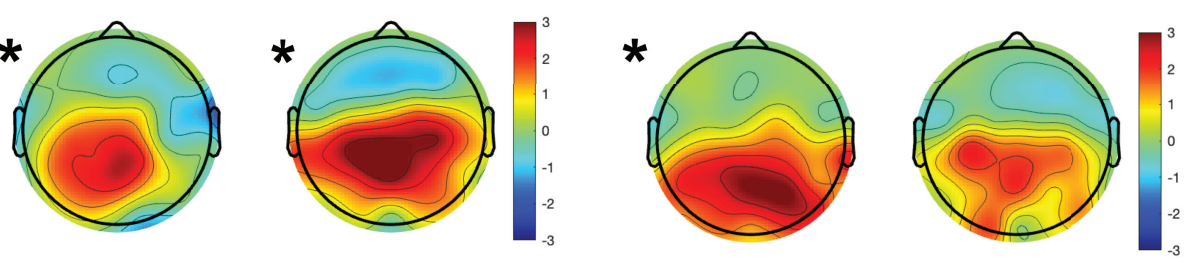
A

B

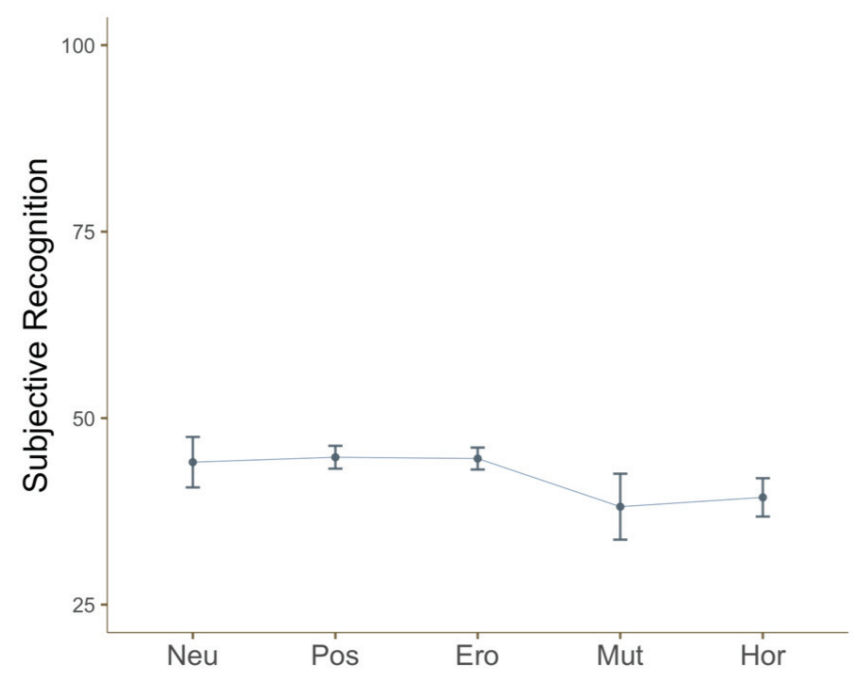

C

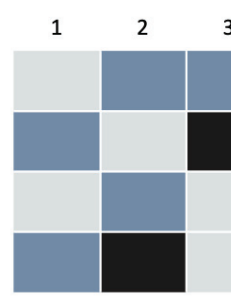

\section{Subjective report about emotional effects on attention} 2nd Part (60 trials):
Recognition memory task e affect you

RT?

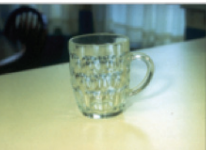

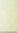

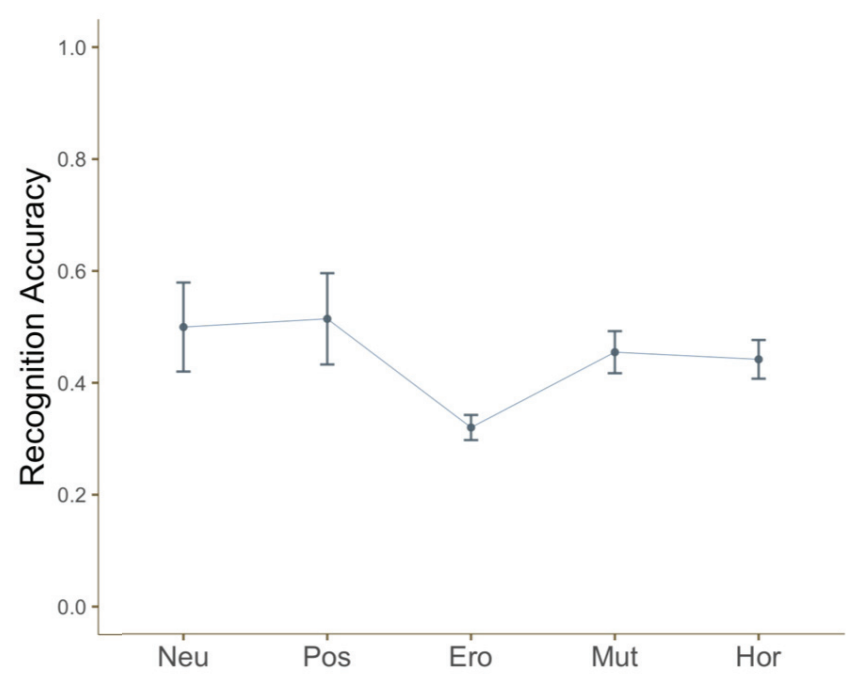

D

$\begin{array}{llll}3 & 4 & 5 & 6\end{array}$

7

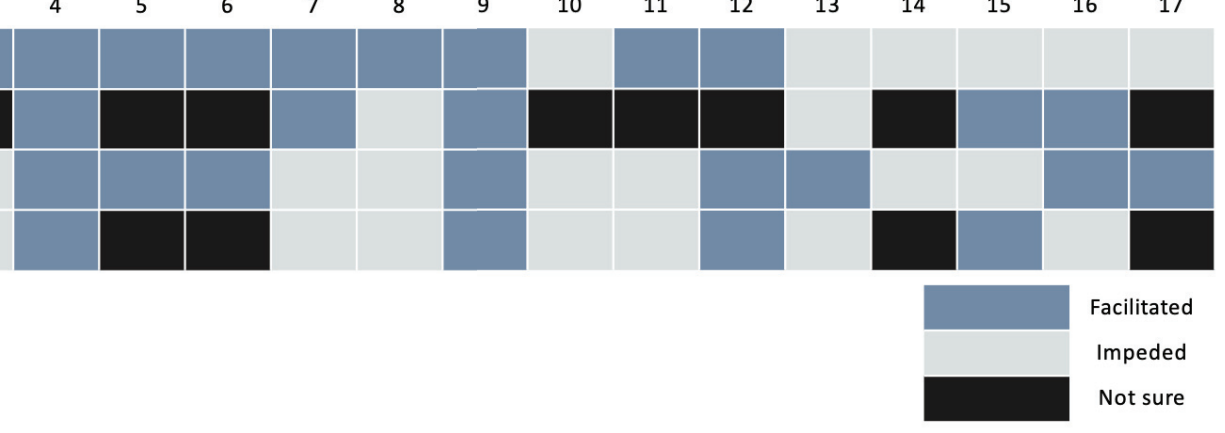

